Volume (3) No. (3) 2020

تصور مقترح لتطوير منهج اللغة العربية للمرحلة الثانوية في ضوء أبعاد الحكمة

د. سعاد جابر محمود حسن

http://dx.doi.org/10.29009/ijres.3.3.8 


\section{تصور مقترح لتطوير منهج اللغة العربية للمرحلة الثانوية في ضوء أبعاد الحكمة}

$$
\text { د. سعاد جابر محمود حسن }
$$

أستاذ المناهج وطرق تدريس اللغة العربية المساعد، ورئيس قسم المناهج وطرق التدريس، كلية التربية

$$
\text { جامعة أسو ان، مصر }
$$

ahmedgaber15@yahoo.com

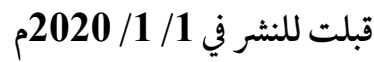

$$
\text { قدمت للنشر في 2019/11/10/ }
$$

ملخص: هدفُ البحث إلى بناء تصور مقترح لتطوير منهج اللغة العربية بالمرحلة الثانوية وفقا لأبعاد

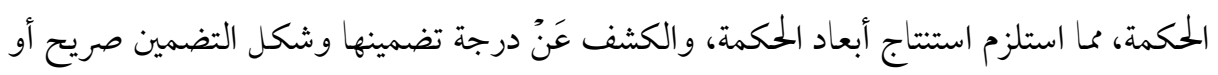
ضمني في منهج اللغة العربية للمرحلةِ الثانوية، ثم باستخدام المنهج الوصفي تم التوصل إلن قائمة بأبعاد الحكمة ضمت ثلاثة أبعاد رئيسية: معرفي ووجداني وسلوكي وتحت كل منها بجموعة مهارات فرعية، وتمت صياغتها في شكل بطاقة تحليل محتوىن، وتكونت عينة البحث من جميع كتب اللغة العربية بالمرحلة الثانوية بصفو فها الثلاثة وعددها خمسة كتب لعام 2018-2019، وكشف التحليل عن تدنئ درجة تضمين أبعاد الحكمة صراحة في منهج اللغة العربية بالصفوف الثلاثة، وكانت النسبة 0,9 ، تم وضع تصور مقترح قائم على توليف أبعاد الحكمة من عدة نماذج وتوزيعها على منهج اللغة العربية بالصفوف الثلاثة. وأوصئ البحث بضرورة وضع سياسات عامة لتطوير مناهج دراسية تتضمن أنشطة قائمة على الحكمة لتنمية قدرة الطلاب على مواجهة العصر الحلالي المليء بالصراعات والتغييرات التكنولوجية والثقافية والقيمية، وتدريب المعلمين في جميع المر احل على تطبيق أنشطة معززة للحكمة في بلمي مقرراتهم، وعلن استراتيجيات التدريس من أجل الحكمة. ومناقشة القضايا المحلية والعالمية في

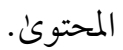

الكلمات الدلالية: التدريس من أجل الحكمة، منهج اللغة العربية، تطوير المنهج. 


\title{
Suggested perspective to develop secondary stage Arabic language curriculum in light of wisdom Dimensions
}

\author{
Dr. Suad Gaber Mahmud Hassan, PhD
}

Associate professor of Arabic Language Teaching, Aswan University, Egypt. ahmedgaber15@yahoo.com

Recived in 10th Novmber 2019

Accpted in 1st January 2020

\begin{abstract}
The study aimed at deducting wisdom components, reveal degree of inclusion of these Dimensions and its form in the Arabic language curriculum for secondary stage, and propose inclusion perspective, using descriptive approach reached a list of principles divided into four areas: goals, content, activities, evaluation. The study sample consisted of five Arabic books in the three grades of 2018-2019. Analysis revealed that the degree to which the components are explicitly included.,9 is very low in all grades. A proposed perspective based on synthesis wisdom dimensions from several models to include these principles in Arabic language curricula developed. The research recommended reformulate Arabic language curricula for other stages by including wisdom in its dimensions and components, specifications of wise behavior, discussing local and international issues in content, and training teachers to teach for wisdom.
\end{abstract}

Key words: wisdom Dimensions, teaching for wisdom, develop curriculum, Arabic language curriculum. 


\section{Summary}

Acquisition of wisdom benefits the individual by broadening his mind, enabling him to solve problems more easily; given the experience and knowledge gained over time, as well as the development of the individual's skills and abilities.

The secondary school has a great importance in the practical and scientific students' life, in which they are prepared for university, and they in this stage need to take a set of decisions.

They are asked to choose between scientific or literary, this choice determines the type of university; And then specialize in work after graduation.

In addition to the abundance of this stage of conflicts and problems; so students need to be trained in the skills of wise thinking so that they can overcome this stage with balance and peace.

The research problem was centered in the weakness of Arabic language curricula because of the boring content and traditional activates, the use of traditional teaching methods, the curriculum makers focus on literary, rhetorical and linguistic aesthetics in the selection of literary texts. Most of them are far from the learner's interest, desires and feelings.

The Arabic language curriculum at the secondary level needs to be developed in light of a number of trends.

It is not an orbit for the student's own creativity that develops his literary and linguistic abilities.

Not to mention that it is analyzed by the authors, which leads to the stuffing of their minds with information without the trouble of thinking, analysis and understanding, which kills their creativity, and lose confidence in themselves, and alienated from the language by the trouble of memorization, and the boredom of indoctrination.

The study then aimed to design a curriculum by adding wisdom dimensions in its goals, content, activates, evaluation. The researcher used in this research descriptive analytical method approach, according to the following steps: 
First: An analytical study of references, research and previous studies related to the subject of research, through the following:

Wisdom concept, models, dimensions, importance, teaching for wisdom, literature and wisdom, secondary school students and teaching wisdom

\section{Second: Determine the list of wisdom dimensions according to the following:}

1. Study and analysis of references, research and previous studies related to wisdom models

2. To determine the list of wisdom dimensions of research and research analysis of wisdom models: Stuadinger \& Baltes (2000), Sternberg (2003), Webster (2007) and Ardelt (2009) and Jeste et al. (2010), identifying similarities and the difference between them. By combining similar aspects of models, a common set of components has been reached.

3. Prepare the list in its final form in accordance with the opinions of the arbitrators.

4. 4.prepare an analysis card using the previous form.

5. 5.Analysis of the Arabic language curriculum using the card: The first to third grade secondary school books (2018-2019) were analyzed and contain a total of 109 lessons, including: literary texts, articles, reading topics, critical concepts, grammatical exercises, topics in literature and rhetoric and the most prominent poets of each poetic school and its characteristics.

\section{Third, designing a curriculum for the three classes as follows:}

Phase I: formulation of a preliminary list of the foundations of the development of the Arabic language curriculum by detailing the dimensions to its sub-component skills through access to the literature and previous studies, and access to the specifications of the objectives, content, activities and evaluation.

- To formulate practical principles that can be applied in formulating objectives and to include the dimensions of wisdom during them, in the selection of content topics and how to present them, and the selection of activities and building methods of evaluation. 
- Presenting the list to a group of arbitrators to confirm the validity of its conclusion, which was amended in the light of their observations and then reaching a list of sixty-two principles.

Phase 2: Design and construction of curriculum:

1. Defining philosophy.

2. Identify and formulate educational goals.

3. Preparation of content and topics.

4. Identification of educational activities.

5. Determination of evolution methods.

6. Determine the time required for teaching

7. Verify the suitability of the proposed curriculum.

\section{Research results, interpretation and discussion:}

The researcher analyzed and extracted the results of research, by answering the following questions:

- What are the dimensions of wisdom included in the educational and psychological writings?

- What is the inclusion degree of wisdom dimensions in Arabic language curriculum at the secondary stage?

- What is the inclusion form of wisdom dimensions in Arabic language curriculum at the secondary stage?

- What are the foundations necessary to develop the Arabic language curriculum according to wisdom dimensions?

- What is the proposed curriculum for developing the Arabic language curriculum at the secondary stage by including wisdom dimensions in its components?

The first question was answered by building a list of wisdom dimensions, second and third questions were answered through the preparation of a an analyses card for Arabic language curriculum the results showed low inclusion degree of wisdom dimensions, the fourth question was answered by reaching a list of sixty-two principles, and the fifth question was answered by building the proposed curriculum. 


\section{Research recommendations}

The discussion and interpretation of the results resulted in the following recommendations and Suggestions:

- Developing public policies to develop curricula that include wisdom-based activities to develop the capacity of public education students to cope with the current era of conflict and technological, cultural and value changes.

- Training of general education teachers at all levels, elementary, preparatory and secondary, in the application of enhanced activities of wisdom and the skills formed in their courses, and in teaching strategies that contribute to facilitate performance related to wisdom.

- Train students to write essays and conduct debates and encourage them to discuss problems and issues using reflective thinking, analytical thinking, and practical thinking.

- Selecting topics of reading and literature from books that show the wisdom of the wise, whether heritage books or contemporary Arabic or translated, and display examples of wisdom, and how to apply wisdom in the lives of students and the current world.

- Clarify the historical and social context of the texts presented so that they can be understood in the light of the data of its time.

- Evaluate using problem-solving and conflict resolution so that part of the grade is devoted to language proficiency and part to the quality of these responses to see if they reflect wise decisions.

- Training students' teachers in faculties of education to teach for wisdom.

\section{Suggested researches}

- An integrative study between science, history and Arabic language to incorporate wisdom through secondary school curricula.

- Analysis of heritage books that dealt with wisdom to derive content for Arabic language books in various stages of education.

- Evaluating the extent to which the Arabic language curricula are included in primary education to the dimensions of wisdom. 
- The effectiveness of a program to train Arabic language teachers on the application of teaching for wisdom.

- Study the effectiveness of building a program to train the student teacher to teach for wisdom. 
خص الله (سبحانه وتعالم) الحكمة بأهمية كبيرة وجعلها مقرونة بكتبه المنزلة، وأعلى من شأن التدبر، والتفكر، واستعال العقل، وقد وردت الحكمة في مواضع متعددة، وقصد بها في آيات معينة الكتب السماوية وقصد بها في آيات أخرى السنة النبوية وقصد بها كذلك الحكم السليم، والحكمة هي قدرة عقلية (ملكة) في الإنسان يستطيع بها أن يصدر حكم) صحيحا، وقد أعطاها الله تعلان للأنبياء، والحكمة التي أعطاها الله تعالمى للأنبياء هي الحكم الصحيح المستنبط من الكتاب. كما يتضح ذلك من قوله تعاله:

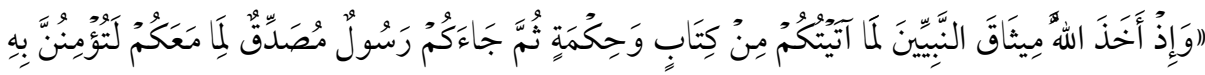

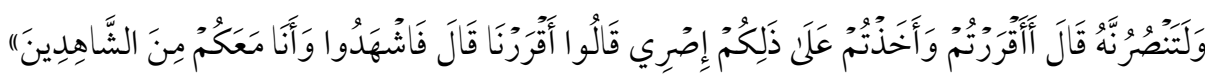

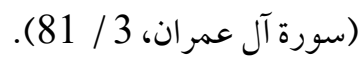

وليست الحكمة خاصة بالأنبياء، بل تعطى للناس كذلك. قال تعالم: "يُؤَتِي الحِكْمَةَ مَن يَشَّاء

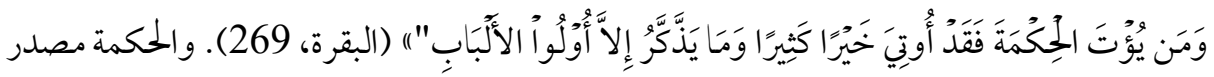
للنوع من الحكم وتعني الحكم الصحيح. وإذا استعملت كالاسم فمعناها الحكم الصحيح أو القدرة التي يستطيع الإنسان أن يصدر حكمًا صحيحًا إذا ملكها. (بايندر، 2016)

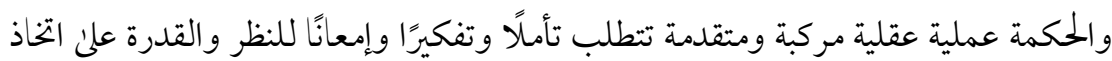
قرار، وتتضمن جوانب عاطفية واجتماعية وشخصية" (الشريدة وآخران، 2013، ص118). (:) ويتسم الشخص الحكيم بالتأمل في مواقف الحياة وفهمها؛ مما يمكنه من اتحاذ القرارات التي تراعنى الصالح العام، فهو يتحرر من الذاتية ويتعمق في الأمور. ويفيد اكتساب الحكمة الفرد في توسيع أفقه، وتمكينه من حل المشكلات والتساؤلات بسهولة أكثر؛ نظر اللخبرة والمعرفة المتحصلة عبر الوقت، وكذلك تنمية المهارات والقدرات التي يتمتع بها الفرد

هـ يتبع البحث أسلوب الجمعية الأمريكية لعلم النفس APA، الإصدار السادس ويتم التوثيق باسم عائلة المؤلف، ويشير

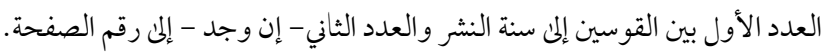
http://dx.doi.org/10.29009/ijres.3.3.8 


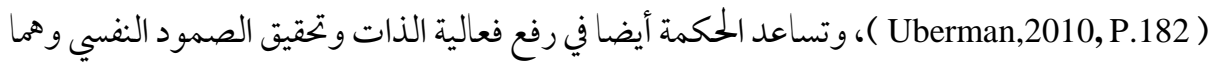
من السمات الإيجابية التي ترتبط بجودة الحياة (عبدالفتاح، حليم،2014، ص 91). وتوظف الحكمة ذكاء الأفراد وقدراتهم الإبداعية، والمعارف التي اكتسبوها في تحقيق إنجازات ذات معني، تؤسس وفق قيم إيهابية تدعم الرغبة في تنمية الذات، والقيام بالأدوار الاجتهاعية المناسبة، و المشاركة في حل مشكلات المجتمع وتطويره. وقد أجمع باحثو الحكمة المعاصرون علن أنها لا تنمو تلقائيًا وتزدادمع العمر ( Ardelt,2010,p193 )، وتحتاج إلى تدريب. و التدريس من أجل الحكمة أحد أبرز الاتجاهات الحميثة التي نتجت عن دراسات الحكمة وأبعادها والتفكير القائم علن الحكمة، وقد ذكر ستيرنبرج Sternberg (2009) أن المدارس ينبغي أن تدرس من أجل الحممة، بأن تجعل الهدف الأساسي من تدريس المعرفة ليس لذاتها ولكن ترقية الصالح العام من خلال التوزان بين المصالح الشخصية والعامة علن كل من: المدئ القصير والمدئ الطويل بالتركيز علن القيم الأخلاقية الإيجابية؛ حيث إن سعادة الفرد والجماعة تعتمد علن اكتساب الحكمة أكثر

$$
\text { من مجرد جمع المعرفة. }
$$

تمثل مناهج اللغة تحديدًا العمود الفقري لكل العمل المدرسي فاللغة أداة التحصيل والتعلم الأولن. و تستمد اللغة العربية أهميتها من كونها لغة القر آن الكريم فهي لازمة للتعبد بتلاوته، ومن دورها كوسيلة اتصال في المجتمع، وحافظة التراث الثقافي، ويهدف تدريس اللغة العربية بالمرحلة الثانوية إلى تنمية مهارات اللغة من استماع وتحدث وقراءة وكتابة، وتنمية مهارات التو اصل، وتنمية قدرته علئ التعبير الشفهي والكتابي عن مشاعره وخواطره ومطالب الحياة اليومية، و غرس القيم الإيجابية الأخلاقية من خلال ما يدرس الطالب من نصوص وموضوعات، وتحسين قدرة الطالب علن استثمار أوقات الفراغ في الهوايات البناءة التي تعود بالخير عليه وعلن المجتمع. إضافة إلى "أن اللغة الآن ينظر إليها كمنتج اجتماعي تستخدم لتعكس كل جوانب المجتمع، ويؤكد التربويون الجانب الأخلاقي والاجتماعي المرتبط باستعمال اللغة في المجتمع" (2010, Uberman). 
وللمرحلة الثانوية أهمية كبيرة في حياة الطلاب العملية والعلمية؛ حيث يتم فيها تأهيلهم

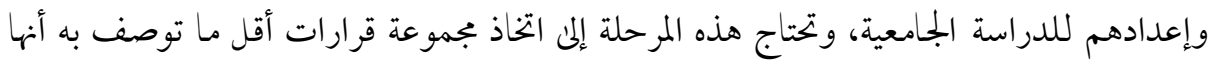

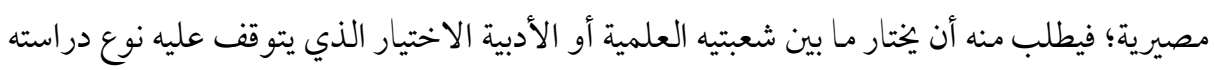

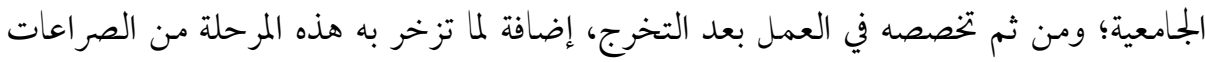
والمشكلات؛ لذا فالطلاب بحاجة إلى الثدريب علن مهارات التفكير الحكيم حتئ يتمكنوا من تخطنى

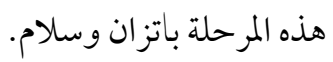

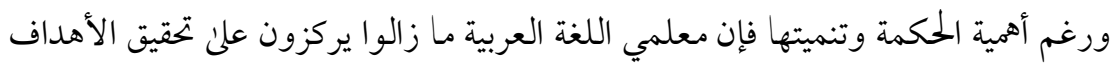

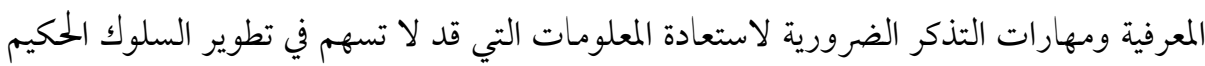

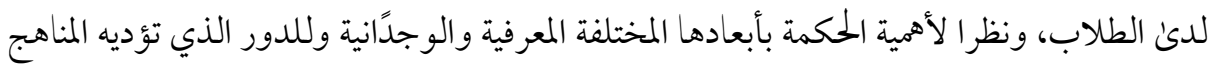

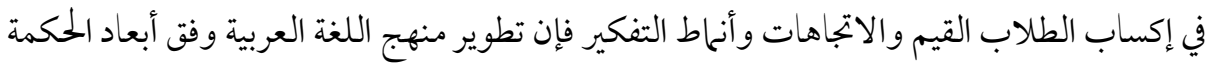

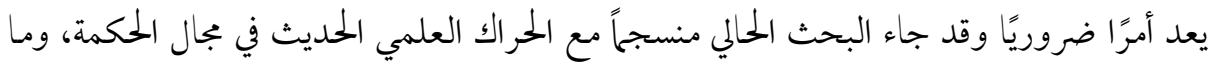

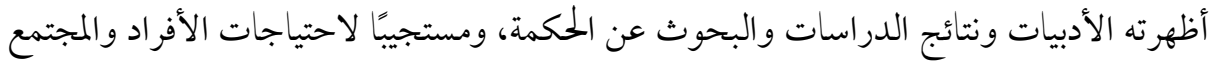

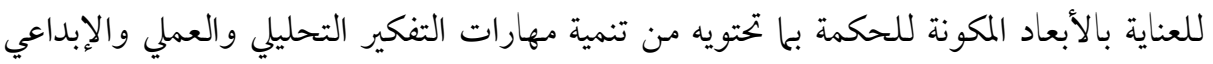
وغيرها لدئ طالب المرحلة الثانوية.

\section{مشكلة البحث}

$$
\text { نبع الإحساس بمشكلة البحث من خلال }
$$

أ- ملاحظة ما يضج به الو اقع من صيحات الطلاب وأولياء الأمور من مشكلات منات مناهج اللغة العربية، والدراسات المتعددة التي قيمت المناهج و أظهرت نتائجها حاجة منهج اللغة العربية

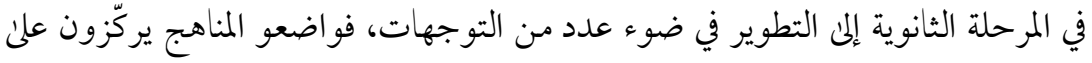

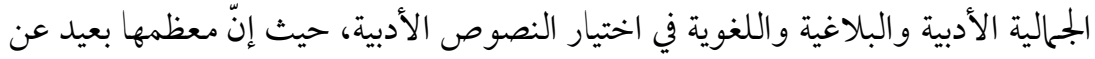

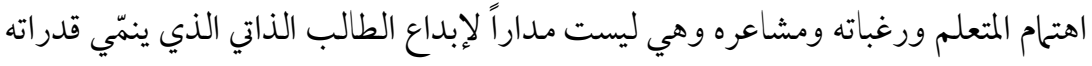

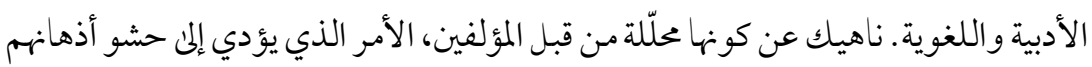


بالمعلومات دون عناء التفكير والتحليل والفهم، مما يقتل القدرة الإبداعية لديهم، ويفقدهم

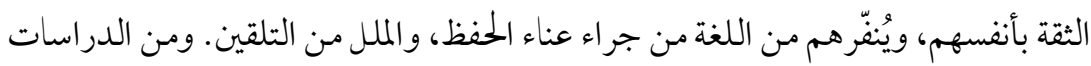
في مصر دراسة (منصور،2014)، ودراسة (السيد،2016)، ودراسة (أحمد سمير 2019)، وفن كثير من دول الوطن العربي وأفريقيا، ومنها: دراسة (غوادرة، 2017) في فلسطين، ودراسة (الجعفري، 2014) في السعودية، ودراسة (جاكاريدجا، 2017) في مالي.

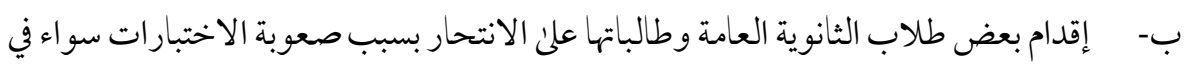

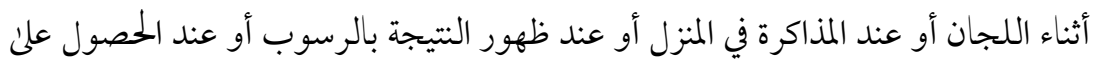

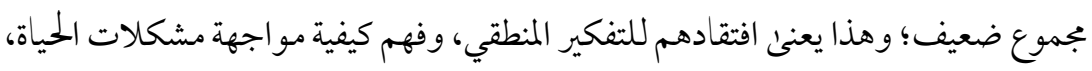

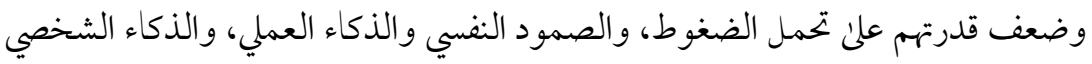

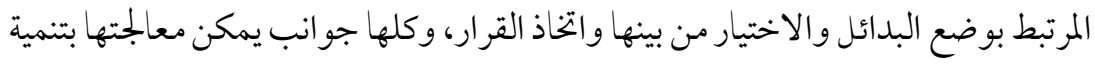
الحكمة، ودللت الدراسات علن ارتباطها بالحكمة ومنها دراسة (شاهين، 2010)

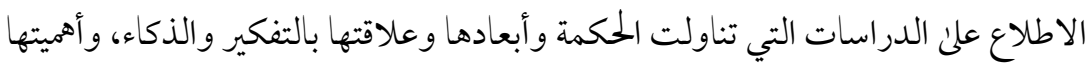

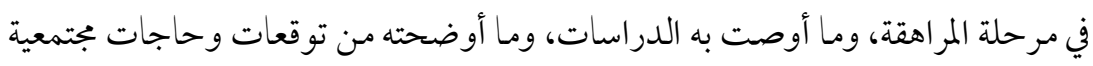
عديدة إلى ضرورة تغير المخطط في الأنظمة التعليمية، ومناهج المدارس التقليدية التي اقتصرت علن تعظيم تلقين المعلومات (Gerver,2010).

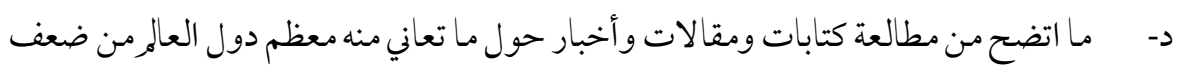

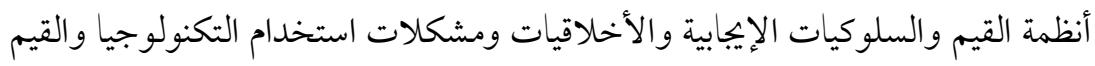

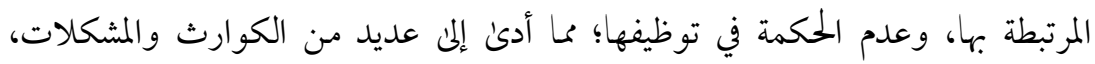

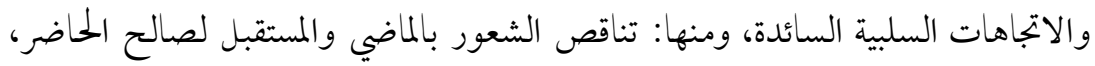

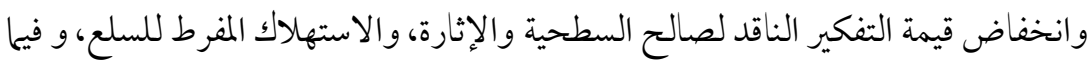

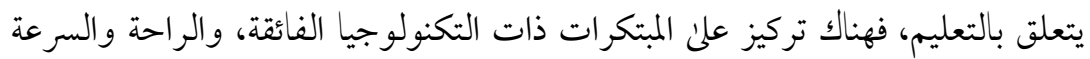

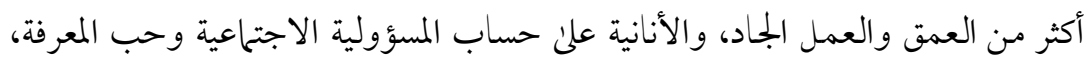


والاتجاه نحو تقديم تعلم مجزا بدلًا من تقديم منهج متكامل (عبد المجيد، 2018) وفي هذا المناخ تمثل تنمية الحكمة من خلال منهج اللغة العربية لدئ طلاب المرحلة الثانوية هدفًا مهرًا

$$
\text { كي تساعد في إعادة التوازن. }
$$

وللتأكد من صدق الإحساس بمشكلة البحث تم استطلاع(:) آراء ثلاثة وعشرين معلمًا من معلمي اللغة العربية ينتمون إلى خمس مدارس ثانوية بمحافظة أسوان حول وجود أبعاد الحكمة في مكونات منهج اللغة العربية بالمرحلة الثانوية: في الأهداف وكذلك دروس المحتوىن والأنشطة وأساليب التقويم وجاءت استجاباتهم كما هو موضح بجدول (1) الآتي: جدول (1) نتائج استطلاع آراء معلمي اللغة العربية بالمرحلة الثانوية

\begin{tabular}{|c|c|c|c|c|c|}
\hline \multicolumn{4}{|c|}{ متوسط نسبة وجود أبعاد الحكمة في عناصر المنهج } & & \\
\hline التقويم & الأششطة & المتوني & الأهداف & عدد المعلمين & الصف \\
\hline$\% 0$ & $\%$ & $\% 38.3$ & $\% 30$ & 9 & الصف الأول الثانوي \\
\hline$\% 0$ & $\%$ & $\% 41$ & $\% 31.25$ & 8 & الصف الثاني الثانوي \\
\hline$\% 0$ & $\% 0$ & $\% 48.33$ & $\% 28,33$ & 6 & الصف الثالث الثانوي \\
\hline
\end{tabular}

ويتضح من استجابات المعلمين تدنئ متو سط نسب وجودها في الأهداف في الصفوف الثلاثة، أما المحتوكن فقد اتفق 100٪ من معلمي الصفوف الثلاثة على وجود بعض أبعاد الحكمة في دروس المحتوى ولكن بنسب متقاربة تراوحت بين 38٪ إلى 48٪، و اتفق 100 \% من معلمي الصفوف الثلاثة على عدم وجود الحكمة في الأنشطة والتقويم؛ مما يعنى أن أبعاد الحكمة غير ممثلة بدرجة كافية في عناصر منهج اللغة العربية للصفوف الثلاثة ويؤكد حاجة المنهج إلى التطوير. لقد أوضح الباحثون في علم النفس الإيجابي والصحة النفسية من خلال ابحاثهم المختلفة رؤاهم حول الحكمة وأبعادها وعلاقتها بكثير من سمات الشخصية والقدرات العقلية والمهارات المعرفية ومر احل تنميتها والعوامل المسئولة عن ذلك؛ مما يحتم علن متخصصي المناهج بدء البحث حول 
رؤى تطبيقية تربوية لتنميتها من خلال تدريس محتوى المناهج المختلفة؛ لذا جاء البحث حول إمكانية تطوير منهج اللغة العربية بالمر حلة الثانوية من خلال تضمينه أبعاد الحكمة. أسئلة البحث حاول البحث الحلاي الإجابة عن الأسئلة الآتية:

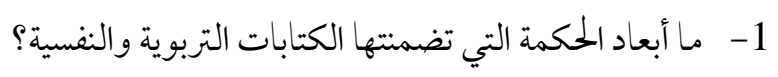

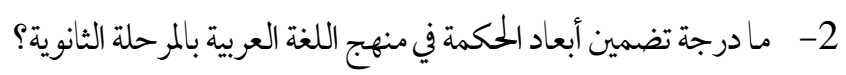

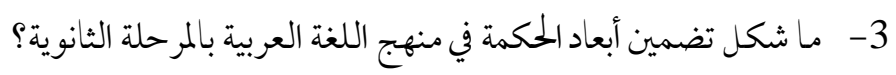

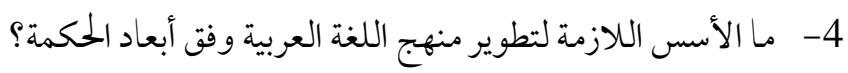
5- ما التصور المقترح لتطوير منهج اللغة العربية بالمرحلة الثانوية بتضمين أبعاد الحكمة في مكوناته؟ الأهداف: هدف البحث إلى 1- استنتاج أبعاد الحكمة التي تضمنتها الكتابات التربوية والنفسية. -2 - ت تحديد درجة تضمين منهج اللغة العربية بالمرحلة الثانوية لأبعاد الحكمة. 3- تحديد شكل تضمين منهج اللغة العربية بالمر حلة الثانوية لأبعاد الحكمة. 4- صياغة الأسس اللازمة لتطوير منهج اللغة العربية وفق أبعاد الحكمة. 5- بناء تصور مقترح لتطوير منهج اللغة العربية بالمر حلة الثانوية وفق أبعاد الحكمة.

منهج البحث: اعتمد البحث على المنهج الوصفي التحليلي وذلك لمناسبته لأهداف البحث. تحديد مصطلحات البحث الحكمة: نظام متكامل من القدرات اللازمة لاتخاذ القرارات في الموضوعات والمشكلات

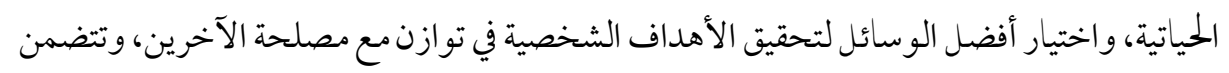
مهارات التفكير الإبداعي والتأملي والتحليلي والعملي، وقبول الجووانب الإيجابية والسلبية للطبيعة البشرية ولأحداث الحياة بما تستوجب من تسامح وتعاطف، واعتراف بنسبية القيم. 
أبعاد الحكمة هي عبارة عن مكونات الحكمة وتضم: جو انب معرفية عقلية: التفكير الإبداعي والتأملي، والتحليلي والعملي، وجوانب وجدانية تتضمن التعاطف والتسامح، وسلوكية تتعلق باتخاذ القرار في المشكلات الحياتية، واختيار أفضل الوسائل لتحقيق الأهداف الشخصية في توازن مع مصلحة الآخرين.

\section{تطوير منهج اللغة العربية}

ويقصد به في هذا البحث أنّه تعديل منهج اللّغة العربية وتجويده بتضمين أبعاد الحكمة المعرفية العقلية و الوجدانية والسلوكية في أهدافه ومحتو اه وأنشطته وأساليب التقويم المتبعة؛ ليصبح أكثر فاعلية في تحقيق الأهداف المنشودة وتنمية الحكمة بأبعادها المختلفة. تضمين: ضمَّن الشَّيءَ الشَّيَ، ضمَّن الشَّيَء في الشَّيء: جعله فيه وأودعه إيّاه (معجم المعاني الجامع)، ويعرف في هذا البحث بأنه: تواجد أبعاد الحكمة في منهج اللغة العربية للمرحلة الثانوية، ويقاس عن طريق رصد تكرار مشاهدة تلك المبادئ في مكونات منهج اللغة العربية من الأهداف والمحتوى و الأنشطة والتقويم. حدود البحث اقتصر البحث على الحدود الآتية - حدود موضوعية منهج اللغة العربية للمر حلة الثانوية وذلك للاعتبارين الآتيين: أ- ينطبق علن منهج اللغة العربية ما ينطبق علن منهج اللغة الإنجليزية الذي اقترح ستيرنبرج رائد أبحاث الحكمة أنه سياق مناسب لتطوير الحكمة لدىن الطلاب؛ مما ينسحب علن مناهج اللغات الأخرىن، ومنها العربية؛ لأن لها الطبيعة نفسها والمكونات وبخاصة من خلال الأدب وموضوعات القراءة، كما تتميز اللغة العربية باحتو ائها علن أدب الحكمة الذي يضم الشعر والثر والحكم والأمثال عبر العصور المختلفة. ب- الثانوية العامة فترة المراهقة التي اتضح من خلال مراجعة أبحاث المراهقة والحكمة أهها فترة أساسية "للتدخلات الرامية إلى تعزيز الحكمة" (Richardson \& Pasupathi, 2005)، كما 
أنها ضمن أخطر المراحل العمرية للإنسان، مرحلة حرجة بها صراعات داخلية وخارجية،

$$
\text { واضطر ابات سلوكية (فاضل،2010) }
$$

- الحدود الزمنية: العام الدراسي 2018-2019.

أهمية البحث

$$
\text { يمكن توضيح أهمية البحث في الآتي: }
$$

- أهمية أبعاد الحكمة التي تعد عاملاً مهمًا يتحكم في ردود فعل الطلاب وسلو كياتهم وقراراتهم في المواقف التعليمية والحياتية، ولا توجد علن حد علم الباحثة دراسات عربية اهتمت

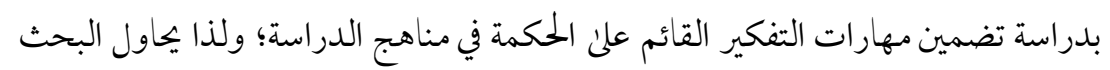
الحالي توضيح كيف يمكن تنمية مهارات التفكير الحكيم في إطار مناهج اللغة العربية. - - الإسهام في تحقيق رؤية 2030 التي تهدف إلى بناء شخصية متكاملـة لمواطن معتـز بذاتـه،

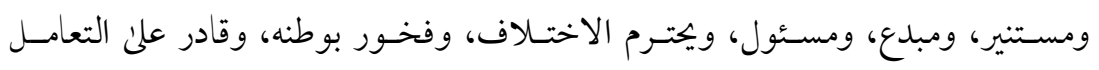

$$
\text { التنافسي مـع الكيانـات الإقليميـة والعالمية. }
$$

- - أهمية وجود إطار علمي عملي يستخدمه مصممو المناهج والقائمون علن تطويرها لتضمين

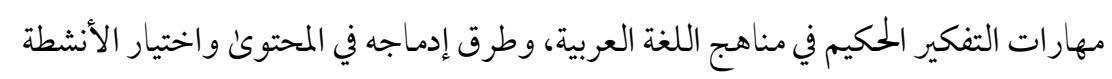
التي تسهم في تنمية مهارات اللغة إلى جانب مكونات التفكير الحكيم، وصياغة الأسئلة المناسبة لقياس مهارات اللغة والحكمة في الوقت نفسه.

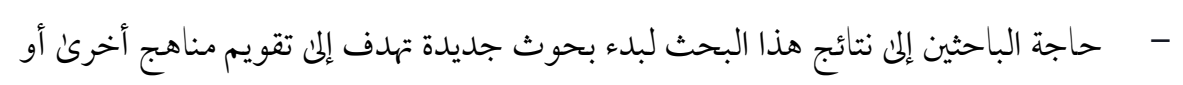

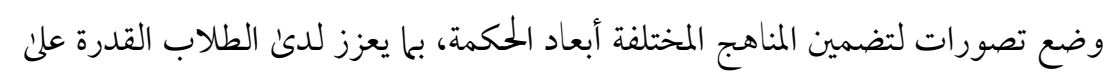
اتخاذ القرار والتصرف بحكمة في الحياة. - - تزويد الميدان التربوي بنموذج لصياغة منهج قائم علن تنمية الحكمة؛ مما قد يسهم في إجراء المزيد من البحوث لدراسة أثره على الجووانب المعرفية والعقلية والاجتماعية والوجدًانية

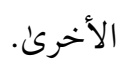




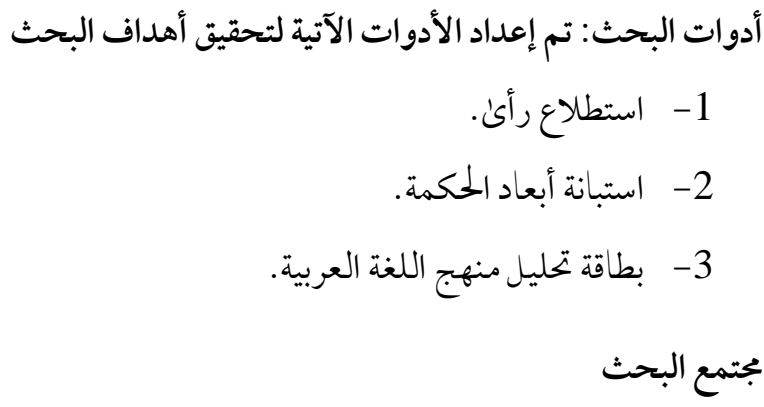

تكون بجتمع البحث من جميع كتب اللغة العربية المقررة علن طلاب المرحلة الثانوية للعام

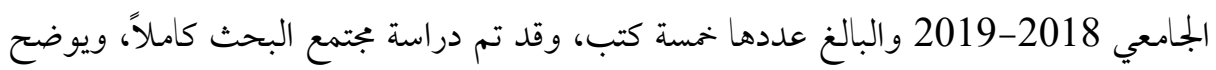
جدول (2) وصفًا للكتب: جدول (2) عينة البحث

\begin{tabular}{|c|c|c|c|}
\hline عدد الصفحات & عدد الدروس & عدد الكتب & الصف \\
\hline 303 & 36 & 2 & الأول \\
\hline 344 & 36 & 2 & الثاني \\
\hline 236 & 37 & 1 & الثالث \\
\hline 883 & 109 & 5 & المجموع \\
\hline
\end{tabular}

الإطار النظري: (الحكمة مفهومها ونج)جها وأبعادها، وأهميتها، والتدريس من أجل الحكمة، والأدب والحكمة، وطلاب المرحلة الثانوية وتدريس الحكمة)

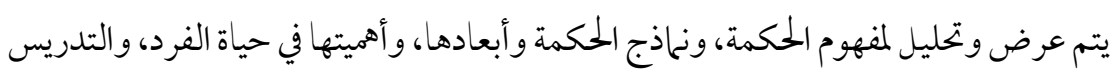
من أجل الحكمة، وتناول الأدب للحكمة عبر العصور المختلفة بدءًا من العصر الفرعوني وانتهاءً بالعصر الحديث، وخصائص طلاب المرحلة الثانوية وإمكانية تدريس الحكمة لهم وأهميته.

\section{مفهوم الحكمة}

للحكمة تعاريف كثيرة تتنوع وفق وجهة نظر معرفها وتخصصه حيث تعرف لغويًا بأنها:" مـا

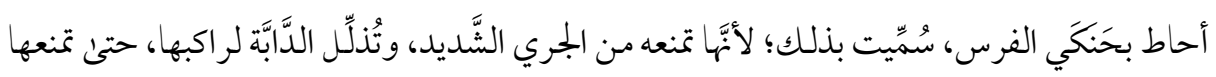
من الجِماح (ابن منظور، ص24262) ومنه اشتقاق الحِكُمَة؛ لأنَّا تمنع صاحبها من أخلاق الأرَاذل.

\section{http://dx.doi.org/10.29009/ijres.3.3.8}




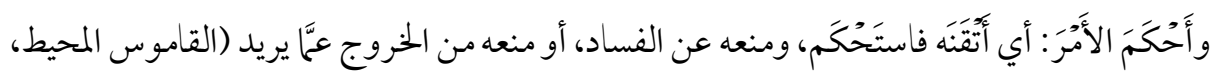
1415)، وعرفها بن منظور (1981، ص 952) بأنها "معرفة أفضل الأشياء بأفضل العلوم والقضاء بالعدل والإتقان في العمل" وقال ابن القيّم (2003،2، ص 449): الحِكُكَمَة فعل ما ينبغي، علن الوجه الذي ينبغي، في

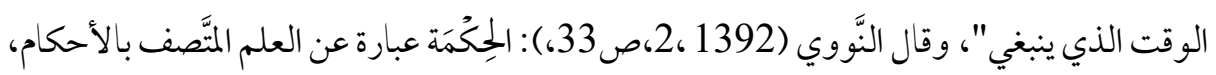
المشتمل على المعرفة بالهه (تبارك وتعلئ) المصحوب بنفاذ البصيرة، وتهذيب النَّفس، وتحقيق الحقِّ،

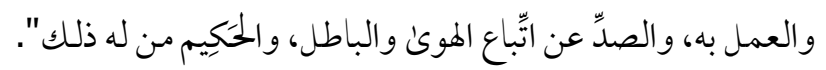

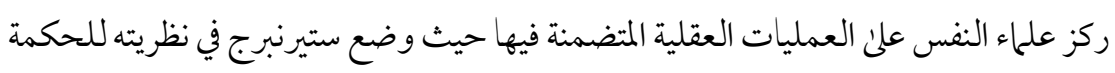
ثلاثة تعاريف، وهي: "تطبيق الذكاء والإبداع والمعرفة ويتخللها القيم الأخلاقية الإيجابية لتحقيق الصالح العام من خلال التوازن بين المصالح الشخصية وبين الشخصية والخارجية علئ كل من: المدني القصير و الطويل"(Sternberg,2001).

Sternberg, والتعريف الثاني أنها" كل ما يؤدي إلى تحسين إدراك الفرد لما يلائمه في الحياة (2003 ، والثالث أنها " التكامل بين المعرفة، والتأمل، والإرادة(Sternberg,2003,p.325)، ووصفها كونزمان Kunzmann ) مأنها: تكامل مثالي للمعرفة والشخصية للعقل و الفضيلة. وذكر شوقي (2006,p.21) Shawqui أن الحكمة تتضمن القدرة علن إصدار الأحكام المناسبة فيا يخص الموضوعات المرتبطة بالحياة واختيار أفضل الوسائل لتحقيق الأهداف. وينظر بعض الباحثين إلى الحكمة باعتبارها خلاصة المعرفة الخبراتية بالحقائق؛ مما يجعل الفرد قادرًا علن الحكم الجيد علنى الأمور الجوهرية في الحياة التي يحيط بها الشك (Baltes \& Smith, 2008) . ويعرف ويبستر (Webster, 2007) الحكمة بأنها :فهم الفرد العميق لذاته وللآخرين والاستخدام النشط للمعرفة، والقدرة علن التعلم من الأفكار والبيئة، مع حدة الذهن Perspicacity ، و البصيرة Insight 
وعرفها كل من ستودنجر وجلوك 2011, p 215 ) Staudinger\& Glück بأنها: امتلاك الصفات الأساسية التي تشكل الخبرة الإنسانية الجلدلية بين الخير والشر، وبين الإيجابية والسلبية، والاعتماد والاستقلال، والشك واليقين، والضبط وعدم الضبط، والأنانية والإيثار، والحكمة تحتضن هذه التناقضات في الحياة وتستخلص الأفكار منها". ووصفها الشريدة وآخران (2013، ص 118) بأنها:" أرقى العمليات العقلية العليا، وتتطلب تفكيرًا ناقدًا، وإبداعيًا، وفوق معرفي، والقدرة علن اتخاذ قرار، وحل مشكلة تهدف إلى الفضيلة والحياة الأمثل."كما ذكر لو وستودنجر Law\&Staudinger ( P.375:2016) أن الحكمة هي ظاهرة معقدة وذات محتوى غنئ تستخدم لوصف البصيرة الإنسانية والشخصية، في حين أن الحكمة الشخصية تصف المعرفة والحكم المتعلق بحياة الفرد، والحكمة العامة تصف المعرفة والحكم حول قضايا جوهرية في الحياة يتعرض لها الفرد. - مات يتضح من التعاريف السابقة أن: - - مفهوم الحكمة له ملامح مختلفة، كل منها يدعم الآخر فالتعاريف النفسية تحمل المعنى اللغوي نفسه، وهي متكاملة فيا بينها يجب مراعاتها عند التدريس. - - - - - الخالق (جل وعلا)، والجوانب الوجدًانية المتعلقة بالنفس وتهذيبها أي تحليها بالأخلاق الحميدة والخصال الحسنة، والجوانب السلوكية وتتضح في قوله إنها فعل ما ينبغي، وتحقيق

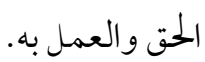
- جاء تعريف ستيرنبرج شاملاً لمعظم أبعادها الأساسية؛ ومن ثم يعد دليلًا علن أنه يمكن تنميتها. - تحد التعاريف عددًا من القدرات العقلية المتطلبة ليتصف السلوك بالحكمة؛ مما يتيح وضع تدريبات لتطويرها. 
- - - - - - مكمة تتضح في اتحاذ القرار والأداء في المشكلات الحياتية؛ مما يعنى أنه يمكن اتخاذ المشكلات الو اقعية الحياتية كموضوعات للمناقشة واكتساب المعلومات و المهارات المختلفة المتعلقة بالسلوك الحكيم. - - - - - - -

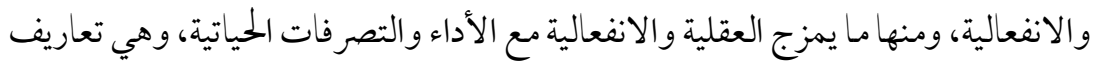
متكاملة تناسب طبيعة الشخصية الإنسانية.

\section{نحاذج الحكمة وأبعادها}

الحكمة كما تبين من تعاريفها السابقة مفهوم متعدد الأبعاد؛ ويتضح ذلك أيضا من خلال

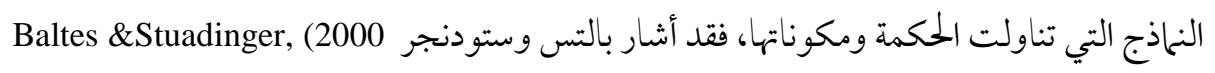
(إلن وجود ستة مكونات للحكمة هي: السلوكيات والتوجهات الإيجابية والاجتماعية وصنع القرارات الاجتماعية، والمعرفة العالمية بالحياة، والاستقرار العاطفي، والتأمل وفهم الذات، ونسبية القيمة و التسامح، والإقرار بالغموض و الشك و التعامل بإيجابية معها. كما أوضح ستيرنبرج Sternberg (2003 ) من خلال نظريته أن الحكمة تتضمن الذكاء العملي و التحليلي والإبداعي، وهئ نوع خاص من حل المشكلات يعتمد علئ المعرفة الضمنية والتوازن، وهيل التوجه نحو الصالح العام، ويتضمن التوازن بين المصالح الشخصية والخارجية بين الأشخاص، و التفكير في متطلبات طويلة المدى' وقصيرة المدىن للمصالح، وتحديد أي استراتيجية تكيفية هي الأكثر حكمة، هل يتكيف الفرد للظروف الحالية؟ أو يحاول تغيير هذه الظروف؟، أو يبعد نفسه عن هذه الظروف؟، وترتبط الحكمة بالذكاء العملي والتوجه القيمي (Jordan, 2005) ويتكون نموذج ويبستر (Webster,2007) من خمسة أبعاد: أولها؛ بُعد التفتح، وهو القدرة على لم إنتاج أفكار مبدعة والبعد عن الاستجابات المتصلبة، وثانيها - بُعد التنظم الانفعالي، ويشمل القدرة علن: استيعاب اختلاف المحيطين، وفهم مشاعر الآخرين، وإعادة إدراك الانفعالات وتنظيمها، وثالثها - بُعد روح الفكاهة، وهو التركيز علن الدعابة ليس بغرض الضحك بل لتحقيق أغراض أخرىن، 
ورابعها -بعدد الخبرة الحياتية الصعبة، وهو المرور بخبرات تتميز بالغموض، والتشابك، والاختيار تحت ضغوط، وخامسها - بُعد التأمل والمبرة، وهو الاستفادة من الماضي في فهم أعمق للمشكلات. ووضع جرين وبراون Brown \&Greene (2009) نموذجًا يتكون من ستة عوامل مترابطة،

معرفة الذات : Self-Knowledge يصف هذا البعد كيف يدرك الفرد اهتماماته الخاصة ومواطن القوة والضعف، والقيم .وتتسم معرفة الذات بأصالة الشخصية والاحتفاظ بصدقها في مختلف السياقات، ومركز نجاح وإنجاز ورضا داخلي فيا يتعلق بالعلاقات

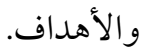

فهم الآخرين : Understanding of Others يصف هذا البعد فهم الفرد العميق لمجموعة متنوعة من الناس في سياقات غختلفة، واهتحام حقيقي بمعرفة الآخرين( الانتباه، والتعاطف)، أو القدرة علن إشراكهم في مداخل أو معالجات مختلفة، والاستعداد لمساعدتهم، وامتلاك مهارات اتصال متقدمة تمكن الفرد من التعبير عن أفكاره بطريقة ذات معنى للآخرين. الحكم Judgment ويشير إلى إدراك الفرد أنَّ هناك طرقًا خختلفة للنظر إلى القضايا عند اتخاذ القرارات، وأن عليه مراعاة بجموعة متنوعة من وجهات النظر حول الماضي و السياق الحلالي، فضلًا عن تأثير خلفية الشخص ذاته، ويتسم الحكيم بحدة الإدراك و البصيرة.

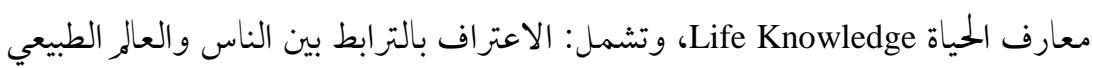
والمعارف والأفكار، والقدرة علن إلقاء نظرة علن المعاني والأسئلة العميقة للحياة والوجود، وتتميز معارف الحياة بقدرة علن فهم القضايا المركزية، وأن يجد الشخص طريقه في الأوقات الحرجة، وفهم حقائق الحياة وعدم يقينيتها علن امتداد العمر. المهارات الحياتية Life Skills ، وهي: الكفاءة العملية، والقدرة علن فهم النظم واستباق المشكلات بأدوات واستراتيجيات للتعامل مع السياقات المتعددة في الحياة، وتشمل المهارات الحياتية القدرة على إدارة الأدوار اليومية المتعددة والمسؤوليات بشكل فعال. 
• الاستعداد للتعلم Willingness to learn ، ويصف اهتحام الفرد المستمر بالتعلم والمعرفة عن العالم، وتتطور الحكمة من خلال التعلم من الحية؛؛ حيث إنها تعكس الخبرات التي تعلموها داخل الصف الدراسي وخارجه، ودمج هذه الخبرات وتطبيقها في حياتهم.

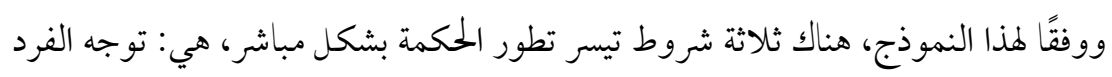
نحو التعلم، والتجارب أو الخبرات، والتفاعل مع الآخرين هذه الشروط تجري في بيئة معينة، وفي سياق يؤثر علن اتجاه الفرد نحو التعلم والتطور، ويغذي هذا السياق الخبرات بمجرد شروع الفرد في العمل داخل تلك السياقات.

وحدد ستودنجر وكيسلر (Staudinger \& Kessler,2009) ثلاثة أبعاد ينبغي أن تتكامل في

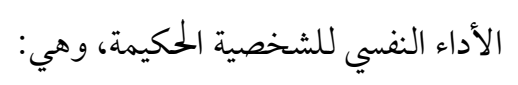

$$
\text { أ- بصيرة عميقة وواسعة عن الذات والآخرين والعالم. }
$$

ب- تنظيم العاطفة المعقدة وما يتطلب ذلك من تسامح مع الغموض.

ج- ولتوجه الدافعي الذي يتجاوز المصالح الذاتية واستثمارها في رفاهية الآخرين والعالم. أما نموذج اردلت فقد ركز علن الجانب التأملي كمكون للحكمة فهو المحفز لارتقاء المكونين المعرفي و الوجدًاني(Ardelt,2009)، وصمم جيست وزملاؤه (Jeste et al., 2010) نموذجًا من ثلاثة

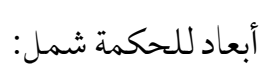

1- البعد المعرفي، ويشير إلى الرغبة في معرفة أعمق لحقيقة الجو انب الشخصية للحياة، وتشمل

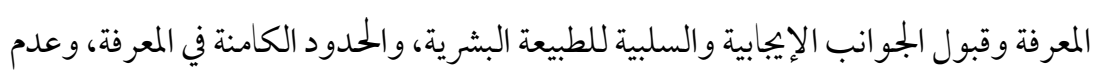

$$
\text { القدرة على التنبؤ بالحياة وعدم اليقين. }
$$

2- البعد التأملي، ويتطلب الفحص الذاتي، والوعي الذاتي، والبصيرة الذاتية لإدراك الظواهر

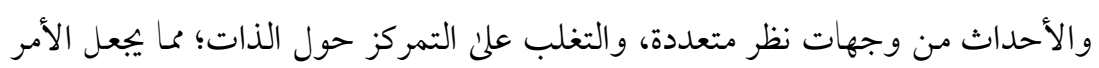

$$
\text { أسهل لفهم دوافع المرء ودوافع الآخرين ومشاعرهم وسلوكهم. }
$$


3- البُعد العاطفي للحكمة الذي يعرف بأنه حب وتعاطف مع الجميع، بما في ذلك الدافع لتعزيز

$$
\text { رفاهية الآخرين. }
$$

كما ذكر لو وستودنجر (Law.\& Staudinger,2016,p375 ) أن الحكمة تتضمن:

$$
\begin{aligned}
& \text { أ- رؤية عميقة وواسعة عن الذات، والآخرين، والعالم. } \\
& \text { ب- تنظيم عاطفي معقد (الغموض والتسامح). }
\end{aligned}
$$

ج- توجه دافعي، وهو تجاوز المصلحة الذاتية، والاستثمار في رفاهية الآخرين والعالم.

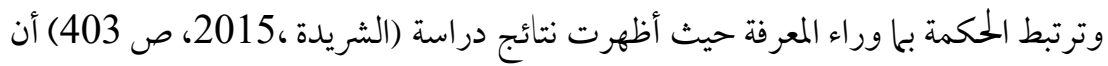
هناك علاقة ارتباطية موجبة بين التفكير ما وراء المعرفي وأبعاده، والحكمة وأبعادها، كما أظهرت أنه يمكن التنؤ بالدرجة الكلية للحكمة من خلال الدرجة الكلية للتفكير ما وراء المعرفي.

$$
\text { ويستفاد مما سبق أن: }
$$

- - للحكمة مكونات متعددة يمكن تلخيصها في ثلاثة أبعاد: البعد المعرفي العقلي، والبعد

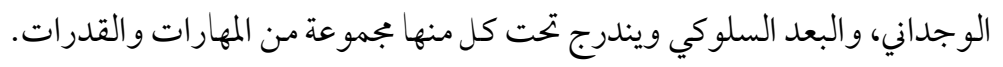

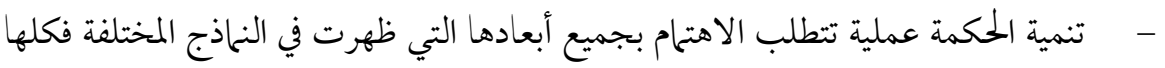
تؤكد التفكير الإبداعي، والتأملي، ومعرفة الذات، وقيم التسامح والتعاطف، وصنع القرار.

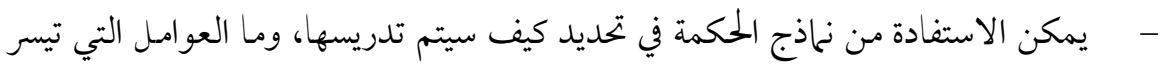

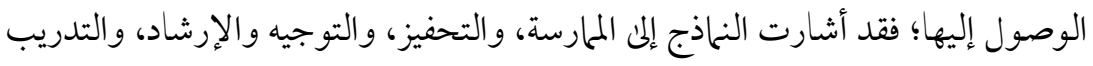

$$
\text { علن حل معضلات الحياة. }
$$

- - هذه الأبعاد يمكن أن تستخدم كمحاور تدور حوها الأشططة اللغوية مثل: كتابة تقرير ذاتي، أو وصف خبرة شخصية؛ مما يتيح دمج القو اعد النحوية أو الأسلوبية في إنتاج معرفة ذاتية.

\section{أهمية الحكمة}

http://dx.doi.org/10.29009/ijres.3.3.8 
تيسر الحكمة الحياة؛ فهي ترتكز علن اتحاذ القرارات الحكيمة التي تحقق للفرد التوازن بين مصلحته ومصالح الآخرين من حوله، وتمكنه من إشباع حاجاته وتحقيق طموحاته بالسبل الإبداعية

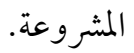

وجعلها رسولنا الكريم (عليه أفضل الصلاة وأتم التسليم) من الأمور التي يحسد عليها الإنسان إن كان متصفًا بها حيث ورد عن ابن مسعود (رضي الله عنه) قال: سمعت النَّي صلن الله عليه وسلم يقول: "لا حسد إلا في اثنتين: رجل آتاه الله مالًا، فسلطه على هلكته في الحقى، ورجل آتاه الله حكمة، فهو يقضي بهاويعلّمها". (البخاري) والحكمة مهمة في الحياة فهي التي تمكن من تغيير العالم تغييرًا إيجابيًا، وعلن المدىئ الطويل

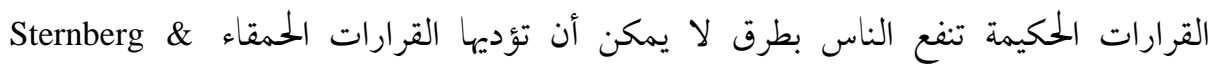
(Grigorenko, 2007) ارتباط إيجابي بين الحكمة والسعادة، وكذلك ارتباط إيجابي قون بين المكون التأملي للحكمة، وأن الحكمة أكثر أهمية بالنسبة للسعادة بين البالغين. فالتفكير الحكيم يعول عليه لحل مشكلات الفرد والمجتمع والعالم بأسره، وهذه الأهمية تستدعن أن يكون هدف النظام التعليمي تنمية الحكمة حلا لمشكلات الواقع المعقدة بدلاً من التركيز على اكتساب المعلومات وحفظها واسترجاعها، وأن تتخذها المناهج الدراسية المختلفة محورا ها تتضح

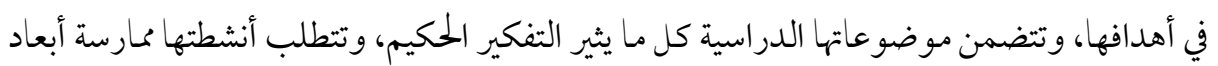
الحكمة، وتقيس أساليب التقويم تلك الأبعاد.

$$
\text { التدريس من أجل الحكمة }
$$

هل يمكن تدريس الحكمة: حاول كثيرون الإجابة عن هذا السؤال حيث ذكر فوكالت Foucault علئ الفروق التاريخية بين الحكمة كمذهب للمعرفة، والحكمة كمارسة تشاركية، إن الحكمة كجزء من الدراسة الأدبية هي على الأقل قديمة مثل المدارس الهلنستية، كما لاحظ كورنو Curnow (2008) أن 
التدريس من أجل الحكمة بدأ تاريخيا منذ عصر الفراعنة حيث ذكر أن" الكتب المصرية للتعليم ركزت

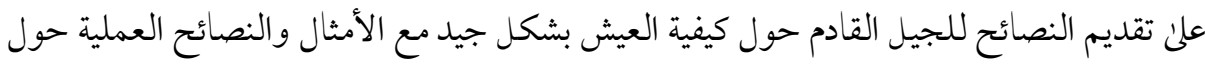
كيفية التصرف في العالر الاجتماعي. وتمت دراسة هذه النصوص في المدارس المصرية منذ 15501100 قبل الميلاد، واستخدمت كمو اد لاكتساب مهارات القراءة واتوات والكتابة.

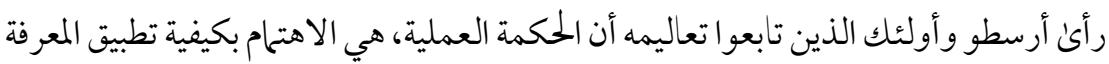
الحكيمة في شكل قرارات جيدة (2011، Curnow). كما أشار ماكلر وستودنجر (2008 \& (Mickler ) Staudinger

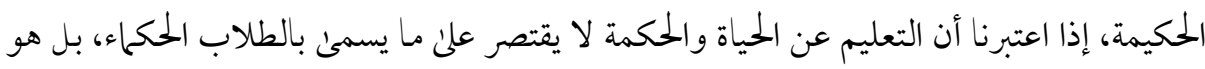
لصالح جميع الطلاب. كما وضع ستيرنبرج Sternberg (2001) مقترحات عملية للفصل، منها: توفير الدعم

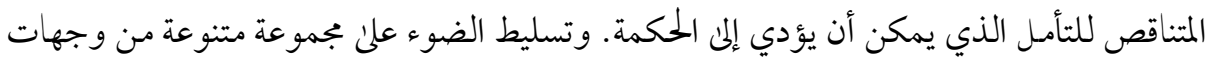

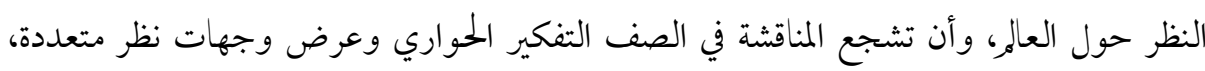
والتفكير الجدلي.

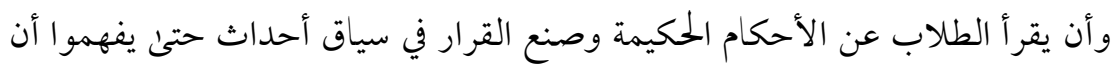

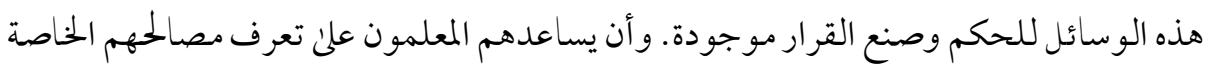

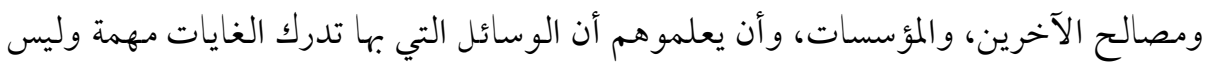

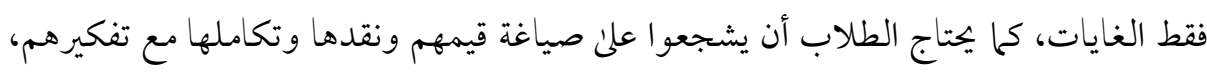

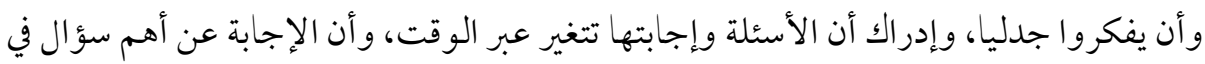
الحياة يتغير من وقت لآخر عبر حياة الفرد. وقد أكد ستيرنبرج Sternberg (2012) ضرورة تعليم الحكمة بذكر أربعة أسباب تحتم تدريس الحكمة، هي: أن المعرفة لر تعد كافية ولا تضمن السعادة والرضا؛ فالحكمة وسيلة أفضل لإنجاز هذه الأهداف، وتوفر الحكمة طريقة جيدة لدمج القيم والتفكير في الأحكام المهمة، وتمثل فضيلة 
لتشكيل عالم أفضل، كما أن هؤلاء الطلاب سوف يصبحون آباء وقادة، وهم جزء من المجتمع الأكبر، وسوف ينتفعون من تعلم الحمىم الصحيح، والتصرف السليم في مجتمعاتهم. وقد ذكر العاسمي ( 2014) أن هناك عددًا من الأساليب يمكن من خلالها تنمية الحكمة، وهى: تحليل محتون الإنتاج الفكري الذي يتسم بالحكمة مثل تحليل محتون كتابات الحكماء، والمـران والتدريـب علن المنطقى، و مجالسـة الحكمــاء وسـؤالهم، وممارسة عملية التنمية الذاتية، وممارسة النقد الذاتي.

يتبين من طبيعة التدريس من أجل الحكمة أن منهج اللغة العربية يمكن من خلاله تدريس الحكمة؛ حيث يمكن ممارسة مهارات التفكير التحليلي من خلال تحليل دروس القراءة لاستخراج أفكارها الجزئية والقيم المتضمنة، وتحليل الأبيات الشعرية لتوضيح أثر البيئة في النص وأثر شخصية الشاعر في كلماته وتعبيراته فهي مهارات لغوية تتطلب أن يفكر الطالب تفكيرًا تحليليًا. كما يمكن التدريب علئ مهارات الإبداع في اللغة وممارسة مهارات التفكير الإبداعي من خلال أنشطة لغوية مثل: تأليف قصص قصيرة أو أبيات شعرية أو جمل نثرية تعبر عن أفكار معينة أو وضع نهاية لقصة معينة. ومحتوى دروس القراءة والأدب يمكن أن يستمد من الخبرات الحكيمة في العصور السابقة و العصر الحلاي كأمثلة علن اتخاذ القرارات الحكيمة أو الحمقاء وأثرها في حياة الفردو الأمة.

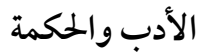

عرف أدب الحكمة في مصر القديمة باسم" Sebayt سباييت أي التعاليم التي ترشد الإنسان للطريق القويم، ومن أشهر حكماء الدولة القديمة الأمير "حور دجد اف" ابن الملك خوفو، والوزير "كاجمنى"و الحكيم "بتاح حتب" و من عصر الانتقال الأول حفظ قدماء المصريين التعاليم التي لقنت للملك "مرىن كارع"، و من عصر الدولة الوسطى حفظوا وصايا الملك أمنمحات الأول لابنه الملك

$$
\text { سنوسرت الأول. }
$$

أما عصر الدولة الحديثة فأشهر تعاليم الحكمة التي تنتمي إليه تعاليم الحكيم "آنى" التي تتميز عما سبقها من نصوص أدب الحكمة بأنها موجهة للعامة و ليس لطبقة النبلاء وتشتمل على حيوية و 
تجارب أكثر مما في التعاليم السابقة و الحكيم "أمنموبئ" ، و التعاليم التي لقنت للوزير كاجمني تناولت

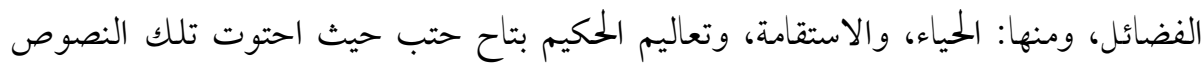
الفلسفية قيمًا عليا، مثل: العدل و الصدق و التواضع و الرمة و ضبط النفس، و تفادن الصراعات

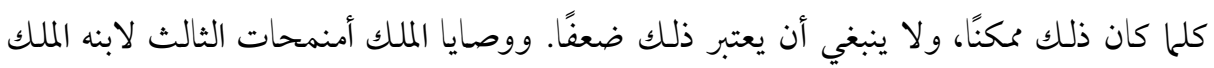

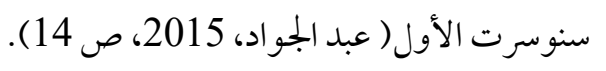

وتعد الحكمة أحد فنون الأدب العربي، جاءت متضمنة في معظم قصائد العصر الجاهلي وخطبه

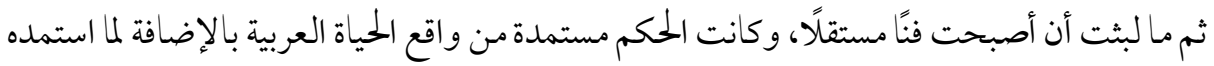

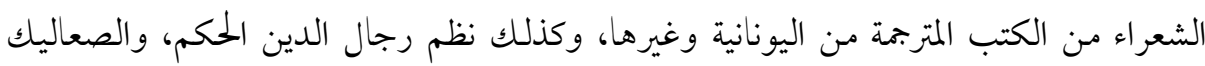

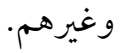

وزخر الأدب العربي منذ العصر الجاهلي بحكماء اشتهروا بأصلة التفكير ودقة الرأي، وأشارت

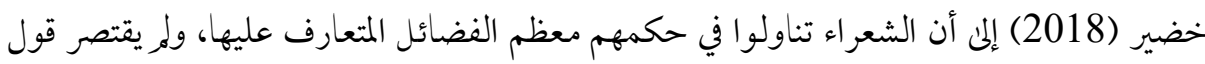

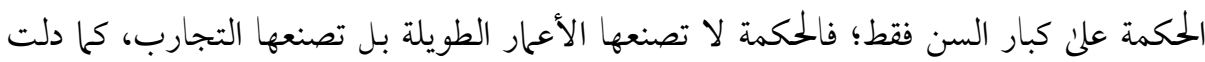

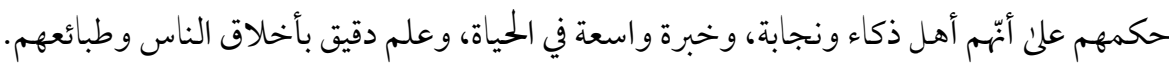

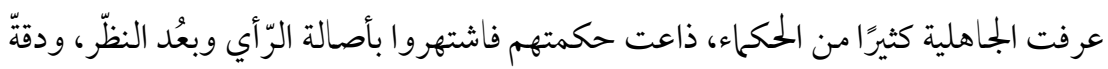

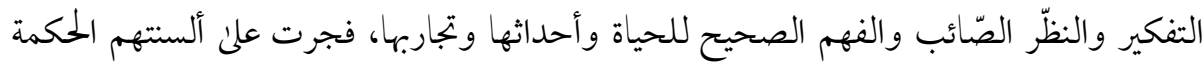

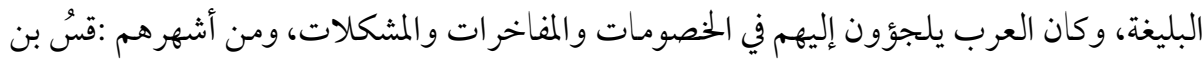

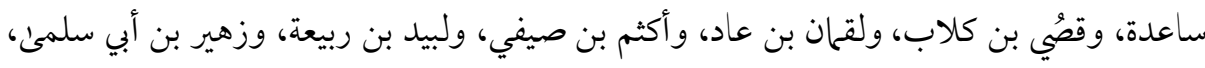

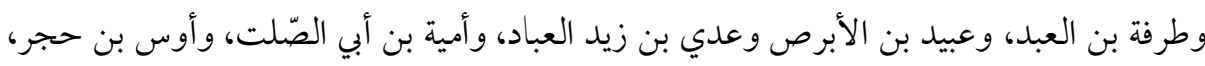
وحاتم الطائي.

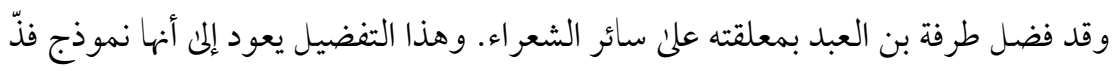

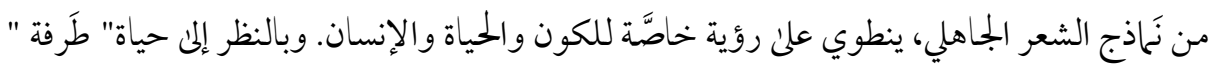


الذي عانئ اليُّم صغيرًا، وعَرف معنى الموت بفقد أبيه - يمكن أن تجد مفتاحًا يبين ملامح فلسفة خاصة مستمدة في الأصل من تجربته الشخصية (العتباني، 2011). وعندما حلل المسعودي (2012، ص: 303) بعض نماذج من أدب الصعاليك باحثًا عن الحكمة فيها وتصنيفها، ووجد أن الحكمة عندهم جاءت مفارقة لعادات القبيلة وأعرافها وقيمها، وانطوت حكمهم علن الخلاص من الفقر، والنجاة من الموت، وحكم المروءة والإغارة. ولما جاء الإسلام برزت أهمية الحكمة بشكل أكبر وتكرر في القرآن الكريم لفظ "الحكمة" في مواضع كثيرة، وورد في أكثر الآيات مقرونا بذكر الكتاب، وأفادلفظ الحكمة في بجمل هذه الآي الدلالة علن ما في الكتاب الكريم من الأحكام والقيم. علن نحو ما ورد في سورة البقرة الآية 129": ربنا وابعث فيهم رسو لاً منهم يتلو عليهم آياتك ويعلمهم الكتاب و الحكمة ويزكيهم، إنك أنت العزيز الحكيم." كما حث الرسول الكريم -صلن الله عليه وسلم- المسلمين علن طلب الحكمة حيث قال: "الحكمة ضالة المؤمن حيث وجد ضالته فليجمعها إليه"، و كان لتعاليم الإسلام تأثير كبير في تغيير قيمة الأشياء والأخلاق في نظر العرب، وتغيرت مقومات الحياة؛ حتى إنه في ظل هذه الثقافة الجديدة التي أخذت تطبع فكر العربي توسعت آفاق المعرفة عنده فانعكس ذلك إيجابًا على نتاج العقل ومن ثم على الن الفكر الحكمي؛ قوة وعمقًا. وفي القرن الرابع الهجري جاء الشّاعر أبو الفتح البستي الذي يعد واحدًا من الشّعراء الحكماء،

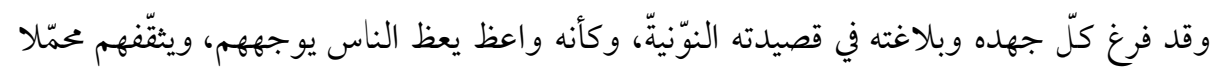
بكثير من التجّارب التّي اكتسبها في حياته الاجتماعية والسياسية، واحتكاكه بالناس والمجتمعات التي عاش بها، وتناول مجموعةً من الفضائل والصّفات ليتحلن بها، وليبلغ هدفه. \& Huseyin (2017)Timurtas

إتجه الأدباء في العصر الأموي اتجاهًا واضحًا إلى أدب الحكمة ومن أشهرهم عبد الله بن المقفع؛ فهو بالإضافة إلى ترجمته لكتاب "كليلة ودمنة" في ميدان الحكمة فإن كتابيه "الأدب الصغير و "الأدب الكبير" يعدان من أدب الحكمة؛ حيث أورد فيها أقوال الحكماء في حسن العلاقة بين الناس والتأدب 
في معاملة الأصدقاء، وغيره كثير من القصائد التي تخللتها الحكم. ومن الشعراء في هذا العصر مسكين

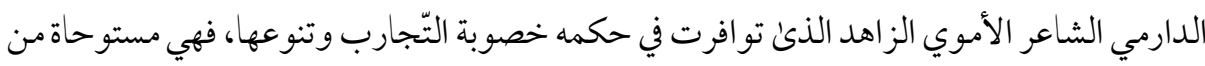

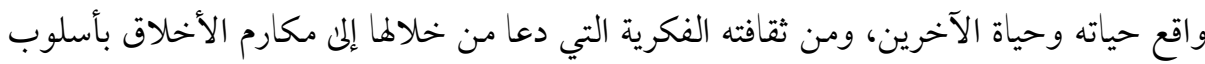
وعظي تعليمي (أبو مصطفى، 2017، ص: وحئ، 61 ) ). وفي العصر العباسي ظهرت التزعة إلى التجديد حيث علت المناداة بمذهب التخير أي "تخير أحسن ما في الحضارات"، وقد تفتح العرب علن ثقافة الحضارات المجاورة له من فارسية ورومية

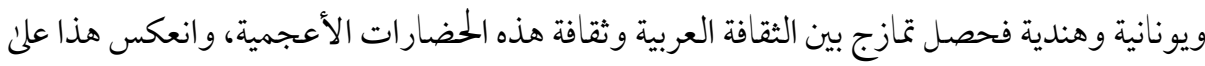
العقل العربي، وازدهرت الحياة الأدبية وتزايدت القصائد التي تزدحم فيها الحكم أو تثار فيها قضايا

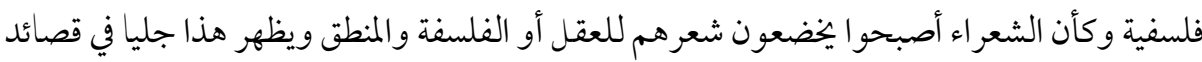

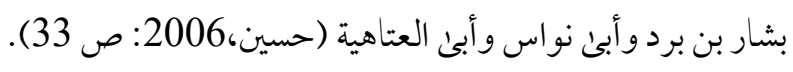
والعصر العباسي هو عصر امتزاج الثقافات الأجنبيّة في سلّة الثقافة العربيّة الإسلاميّة. فكان الثان حاصل المزيج الفكري والعقلي والعرقي ثقافة جديدة متأثرة بالثقافات الهنديّة والفارسيّة واليونانيّة. ونقل الكتب وترجمتها من هذه الثقافات إلى العربيّة، ومن أهم عطات العلوم: الوراقين، والمساجد،

$$
\text { ومجالس الخلفاء (البوغبيش، 2012). }
$$

وفي عصر الطو ائف ذكر (محمود، 2014، صان 3) أن شعر الحكمة كان فيه دعوة الشعراء الناس بصورة عامة ينصحونهم ويرشدونهم عإنى ترك ملذات الدنيا، واللجوء المى الله تعلان، والعفو عن الناس،

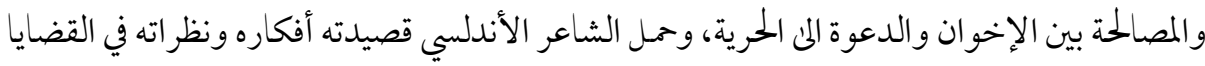

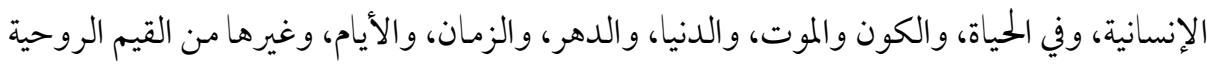

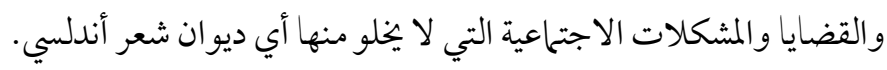

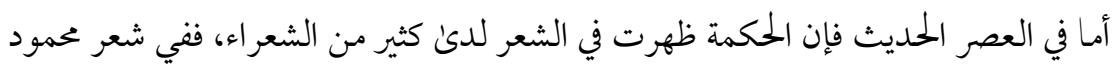

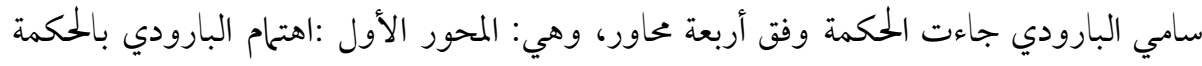
وقناعته الشخصية بأهميتها في الحياة حيث يقول :إن من الحكمة البليغة للروح غذاء الماء كالطب للأجسادِ، 
و المحور الثاني: النظرة للحياة والموت وللدهر وتقلباته، والمحور الثالث يتعلق بنظرته للحب، والمحور الرابع يدعو فيه إلى التحلي بمحاسن الأخلاق والتنفير من مساوئها ( Muhammad,2017)، كما توصل الدوسري (2008 )إلى غزارة الحكمة في شعر شوقي، و تعدد مصادرها عنده، و انقسامها إلى قسمين: عملية ، ونظرية، و تنوع مواقع أبيات الحكمة في قصائده. إن ما سبق يعد نظرة سريعة على علاقة الأدب في عصوره المختلفة بالحكمة، وهذه النظرة تعطى لئى إشارة إلى غنى اللغة العربية بالحكم عبر عصور الأدب المختلفة، فلم يخل عصر منها ولم تخل قصيدة من حكمة، فالعرب أهلها يستحقون أن يربئ أبناؤهم علن حكم أجدادهم ليفيدوا منها في حياتهم الحالية. ويستفاد مما سبق:

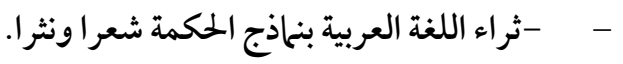
- - - - - مككن تقسيم العصور على سنوات الدراسة الثلاث بحيث يدرس الطالب في كل عام نحاذج من شعر الحكمة ونثرها، بها يتو افق ويتكامل مع مفردات منهج التاريخ.

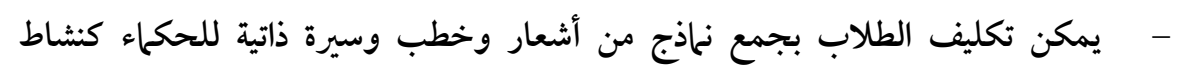

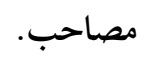

طلاب المرحلة الثانوية وتدريس الحكمة المرحلة الثانوية باعتبارها مرحلة دراسية لها أهميتها الكبرى في حياة الفرد فبناء علن اختيارات الطالب يتشكل مستقبله العلمي، ومن ثم العملي، و كمر حلة نمو هي من أخطر مر احل الحياة بها كثير

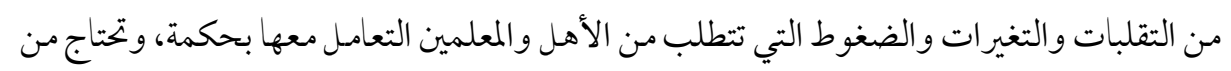
الطالب جهدًا كبيرًا لاجتيازها بسلام؛ وبينت الدراسات أنه يمكن تنمية الحكمة في هذه الفترة حيث أجرى بالتيس وزملاؤه (Baltes et al,2001) در اسة حول استكشاف الحكمة لدئ المراهقين وعلاقتها بالمعرفة والحكم مع عينة غير متجانسة مكونة من 146مر اهقاً انحصرت أعمارهم فيما بين 14-20 سنة وعينة مقارنة مكونة من 58 راشداً فيما بين 21-37 سنة، وأشارت النتائج إلى أن فترة المر اهقة هي فترة مهمة للتنمية المعيارية المتدرجة في المعرفة حول مشكلات الحياة الصعبة. 
وذكرت ارديلت Ardelt (2004) أنه خلال سنوات المراهقة يبدأ تعلم كثير عن الخطوات العملية الأساسية للحياة، و لاحظ ستيرنبرج Sternberg (2005) أن الأبحاث حول علاقة الحكمة بالعمر أن هناك رؤين خختلفة بعضها يتباً بالمكاسب وبعضها يتوقع الأقل، و الذين أجرو امعظم البحوث التجريبة في هذا المجال وجدوا أن الحكمة ليست بالضرورة ناتج العمر، وقد وجد ماكلير Mickler (2008) أن الحكمة الشخصية ظهرت عبر سن الرشد وهذا يعنى أنه بالنسبة لمعظم الناس تعلم الحكمة الشكلية يحدث قبل الرشد.

كما درس باسوباز وريتشاردسون Pasupathi \&Richardson (2005) التطورات النفسية في سنوات المراهقة التي تدعم ظهور الحكمة، وتشير الأبحاث حول التطور العقلي وتعرف الذات، وتطور الشخصية خلال المراهقة إلى تحسن في التفكير التأملي الذاتي، وتطور إحساس الفرد بذاته، وزيادة التفتح العقلي. فحص بلوك وجلوك Bluck and Glück (2004) قصص الحكمة الشخصية لمراهقين في سن 20-15 سنة، وشباب 30-40 وبالغون أكبر 60-70 سنة ووجدوا أن المر اهقين مثل البالغين أشاروا المي مو اقف حياتية أساسية ورأو أن الأفعال الحكيمة هانو اتج إيجابية مثلما رأنى الكبار ذلك، ولكنهم كانوا أقل قدرة من الكبار في استخلاص الدروس من السياق ضمن قصص الحياة الأوسع. ومن أكبر الأسباب التي يجب بسببها تدريس الحكمة لطلاب المرحلة الثانوية المغالطات التي استخلصها ستيرنبرج (Sternberg, 2005) في التفكير مرتبطة بالمر اهقين، وهي: - مغالطة التفاؤل غير الو اقعي: تظهر عندما يعتقد شخص أنه أكثر ذكاءً أو قوة، ولا يقلق بشأن

$$
\text { المخرجات وبخاصة طويلة المدى فكل شيء سيكون على ما يرام. }
$$

- مغالطة الذات: تظهر عندما يعتقد شخص أن مصالحه هي فقط المهمة، ويبدأ في تجاهل

$$
\text { مسئولياته نحو الآخرين والمؤسسات الأخرىن. }
$$

- مغالطة العلم المطلق: تنشأ عن مغالطة توفر أي معرفة تحت تصرف المرء قد يحتاجها وينظر الناس إلى القادة علن أنهم مطلعون للغاية أو حتى قريبون من المعرفة. 
- مغالطة القدرة المطلقة: ناتجة عن القوة المتطرفة التي يستخدمها المرء، أو التي يعتقد المرء أنه

$$
\text { يمتلكها. والتيجة هي التوسع المفرط وإساءة استخدام السلطة. }
$$

- مغالطة الحصانة: تنبع من وجودوهم الحماية الكاملة حيث يبدو أن الناس -وخاصة القادة- لديهم

$$
\text { عديد من الأصدقاء المستعدين لحمايتهم في أي لحظة. }
$$

- مغالطة أخلاقية: فلك الارتباط يجدث عندما يبدأ المرء في الاعتقاد بأن الأخلاق مهمة للأفراد

$$
\text { الآخرين وليس لنفسه. والاعتقاد بأنه غير مطالب بإعال المعايير الأخلاقية التي يجملها. }
$$

ودرست بانج Bang (2009) العلاقة بين الحكمة وهوية الذات لدئ المراهقين الكوريين

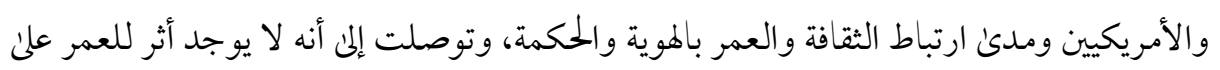

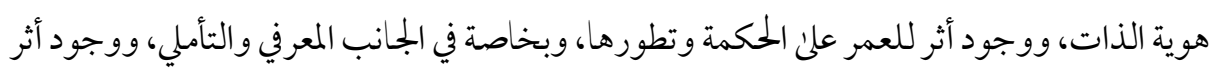
دال للثقافة علن الحكمة.

واختبرت أرديلت (2010) Ardelt طلاب الجامعة الأمريكية وله تجد فروقًا دالة في درجات الحكمة بناء على العمر بالنسبة للذين قيمتهم، ووجدت أن البالغين الأكبر سنالم يحرزوا درجات أعلى من طلاب الكلية؛ مما دعم الر أي بأن الحكمة لا تنمو تلقائيا، كما أظهرت نتائج دراسة الياسري (2011)

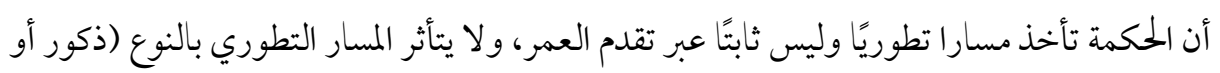

$$
\text { ومما سبق يتضح أن: }
$$

- - تنمية الحكمة في الأعمار الأصغر أكثر فعالية؛ مما يقتضي تنميتها في المرحلة الثانوية. - - تضمين الحكمة في المناهج يتطلب أن تدمج القدرات العقلية والانفعالية والمهارية المتطلبة

$$
\text { لأبعاد الحكمة المختلفة في الأهداف مع نواتج التعلم الخاصة بالمادة الدراسية. }
$$

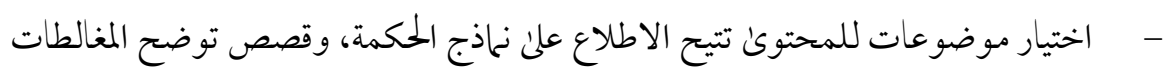

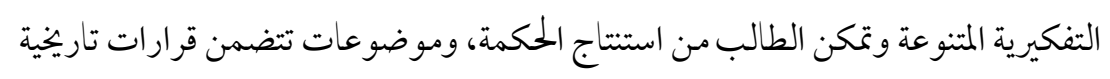
حكيمة وأخرى غير حكيمة ليتأمل الطالب آثار كل منها. 
- - تنمية الحكمة تتطلب تطبيق أنشطة تنمئ مهارات التفكير الإبداعي والناقد مثل المناظرات

$$
\text { وإجر اء الحوارات، والندوات. }
$$

- - يتطلب قياس الحكمة أساليب تقويم تعتمد علن حل المشكلات الحياتية وتطبيق المهارات

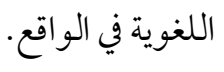

$$
\text { إجراءات البحث }
$$

1- ل للإجابة عن السؤال الأول من أسئلة البحث الذي نص على:" ما أبعاد الحكمة التي تضمنتها

$$
\text { الكتابات التربوية والنفسية؟ }
$$

أ- الاستفادة مما تم مراجعته خلال النقاط السابقة في الإطار النظري من نماذج الحكمة.

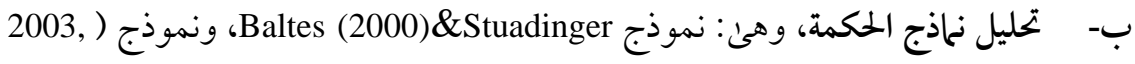
Sternberg ونموذج (Ardelt,2009 ) و نموذج (2007،Webster ) ونموذج جيست وزملاؤه (Jeste et al., 2010)، وتحديد جوانب التشابه والاختلاف بينها. وبضم الجحوانب المتشابهة في النحاذج تم التوصل إلى بجموعة مكونات مشتركة بين النماذج. ج- وضع القائمة المبدئية في صورة استبانة والتحقق من صلاحيتها: د- تم تنظيم القائمة المبدئية في شكل استبانة): تتصدرهاصفحة للبيانات العامة، وصفحة تشتمل علن مقدمة تشرح للقارئ الهدف من الاستبانة، ودوره في الاستجابة لبنودها، وتم عرضها على عددمن المتخصصين (:) في المناهج وطرق تدريس اللغة العربية وعلم النفس لإبداء الرأي في القائمة المبدئية لأبعاد الحكمة من حيث سلامة الصياغة، وصحة التصنيف، وقد أسفرت هذه الخطوة عن مو افقة المحكمين علن انتحاء العبار ات للمحاور الموضوعة لها، وتعديل صياغة

$$
\text { بعض العبارات. }
$$

ه- التوصل إلى الثكل النهائي لقائمة أبعاد الحكمة

$$
\begin{aligned}
& \text { 10. انظر ملحق (2 ) استبانة أبعاد الحكمة. }
\end{aligned}
$$

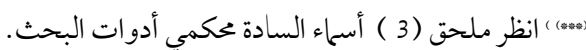

http://dx.doi.org/10.29009/ijres.3.3.8 
و - بعد إجراء التعديلات التي اقترحها المحكمون انتهي الأمر إلى وضع القائمة في شكلها

$$
\text { النهائي كما هي موضحة بجدول (3) الآتي: }
$$

$$
\text { جدول (3) أبعاد الحكمة ومكوناتها }
$$

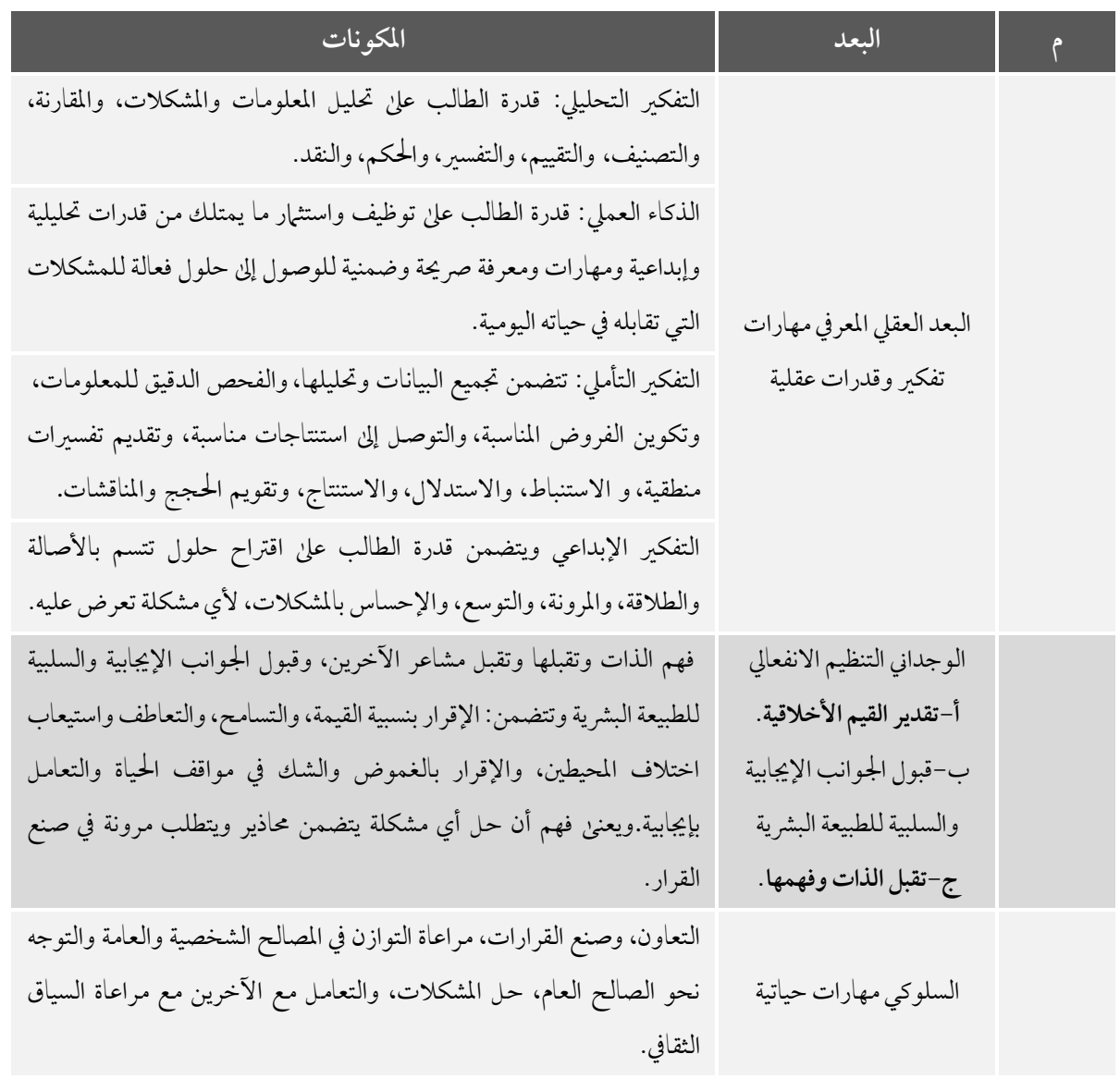

- - - - -لإجابة عن السؤالين الثاني والثالث من أسئلة البحث: مـا درجة تضمين أبعاد الحكمة في منهج اللغة العربية بالمرحلة الثانوية؟ وما شكل تضمين أبعاد الحكمة في منهج اللغة العربية بالمرحلة

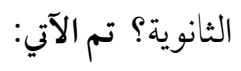

أ- تحويل قائمة الأبعاد التي تم التوصل إليها في المرحلة السابقة إلى بطاقة لتحليل منهج اللغة العربية. تكونت من أحد وأربعين بندًا، ووحدات التحليل هي الجملة سو اء أكانت هدفًا 
أم نشاطًا أم سؤالًا، وتم تحديد درجات التضمين لتكون درجة التضمين كبيرة جدًا، وكبيرة، ومتوسطة، وقليلة، وقليلة جدًا بحسب النسبة المئوية لتكر ار ظهور البعد، وشكل

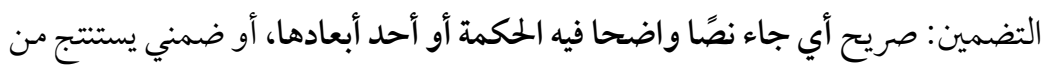
ثنايا النصوص أو العناوين الفرعية ها أو الأنشطة المصاحبة للدرس. ب- التحقق من صدق البطاقة وثباتها: تم الاستدلال علن صدق عملية التحليل من خلال تعرف صدق المحكمين حيث تم عرض أداة التحليل علن مجموعة من المحكمين

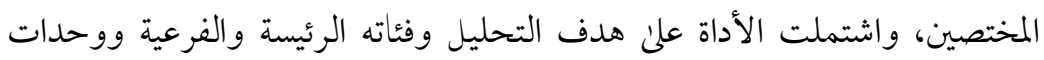
التحليل لمعرفة مدن شمولها وتم التعديل وفقًا لآرائهم.

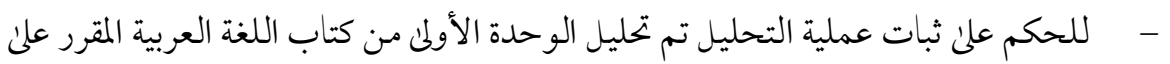
طلاب الصف الثالث الثانوي، ثم إعادة التحليل بعد أسبو عين وحساب نسبة الثمات الثبات بتطبيق

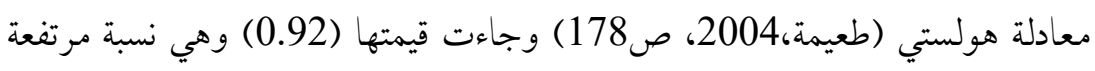

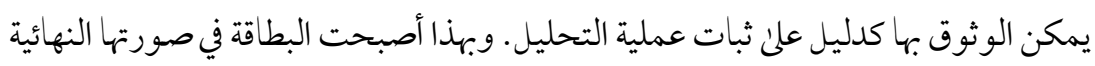

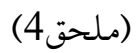

ج-تحليل منهج اللغة العربية باستخدام البطاقة: تم تحليل كتب الصفوف من الأول إلن الثالث الثانوي طبعة (2018-2019) وتحتوين إيمالاً علنا 109 درسًا، تشمل: نصوصًا أدبية ومقالات وموضوعات قراءة ومفاهيم نقدية وتدريبات نحوية،

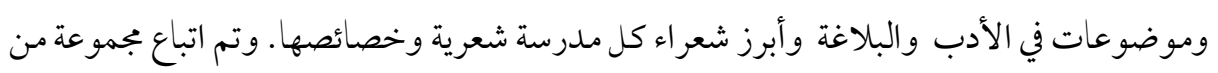

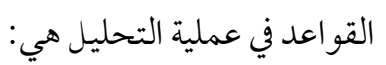
أ- اعتبار العناوين الرئيسية والفرعية في الدروس والأهداف التي تسبق كل منها، والأنشطة

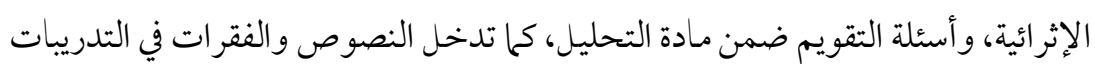

النحوية ضمنها.

ب- قراءة جميع موضوعات الكتب قراءة متأنية لتحديد مدئ تضمنها لبنو دقائمة التحليل. 
ج- رصد تكرارات ظهور أبعاد الحكمة في كتب اللغة العربية وحساب النسب المئوية لهذا التكرار وبناءً علن ما تم مراجعته في الدراسات السابقة تم اعتماد النسب المئوية الآتية في تفسير التنائج:

$$
\begin{aligned}
& \text { - - - - } \\
& \text { - - 19-70\% درجة تضمين كبيرة. } \\
& \text {-69-60 - - } \\
& \text { - 50-59\% درجة تضمين قليلة . } \\
& \text { - - أقل من 50٪ درجة تضمين قليلة جدًا. }
\end{aligned}
$$

و الجلداول: 4، 5، و 6 بملحق (5) توضح نتائج تحليل كتاب كلصف من حيث درجة تضمين أبعاد الحكمة وشكله في منهج اللغة العربية للصفوف الثانوية الثلاثة:

$$
\text { أولًا-نتائج تحليل منهج اللغة العربية للصف الأول الثانوي }
$$

تم حساب تكرار ظهور أبعاد الحكمة في منهج اللغة العربية بالصف الأول الثانوي أهدافه،

$$
\text { ومحتواه، وأنشطته، وأسئلة التقويم به ونسبته المئوية فاتضح ما يبينه شكل (1) الآتي: }
$$

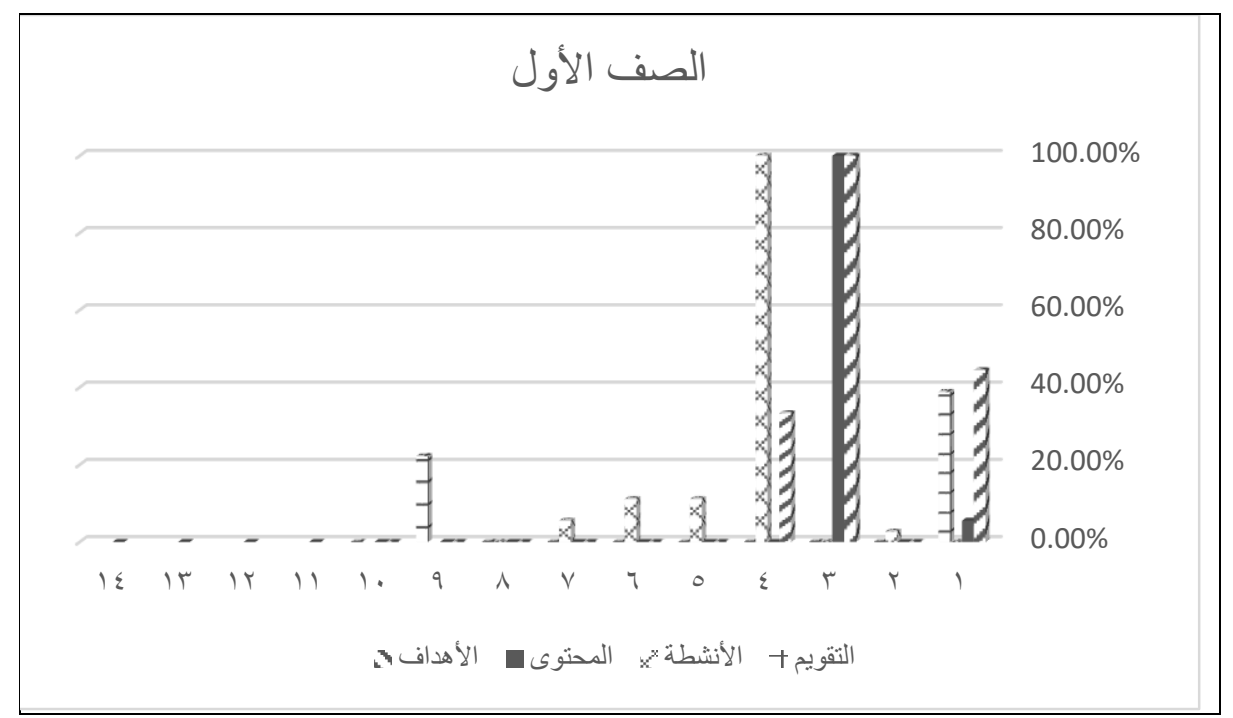

شكل (1) - 1) - 1) 


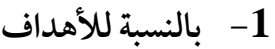

أ- نصت أهداف الدروس علن تنمية القيم الأخلاقية بلدرجة كبيرة جدًا بنسبة 100٪حيث احتوى كل درس علن قيمة أخلاقية معينة مثل الكرم، والتسامي، وقيم الحياة الزوجية وبشكل صريح؛ وهذا مما يحمد لو اضعي المنهج اهتمامهم بالقيم الأخلاقية وجعلها مثثلة بدرجة كبيرة جدًا، كما تضمنت الأهداف تنمية مهارات التفكير الإبداعي بدرجة قليلة جدًا بنسبة 44.4٪ وبشكل صريح، لكنها اقتصرت علن مهارة واحدة هي الطلاقة في اقتراح العناوين أو الحلول، وتنمية مهارات التفكير التحليلي بدرجة قليلة جدًا بنسبة

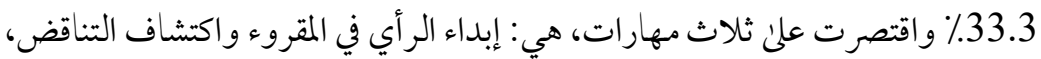
و التمييز بين الحقيقة والادعاء. ب- خلت أهداف المنهج من أبعاد الحكمة الأخرىن، وهي: مهارات الذكاء العملي، ومهارات التفكير التأملي، وقبول الجو انب الإيجابية والسلبية للطبيعة البشرية، والتعاون، والتنظيم الانفعالي وتقبل الذات وفهمها، ومر اعاة التوازن بين المصالح الشخصية والعامة والتوجه نحو الصالح العام، واتخاذ القرار، ولرتعالجها لا صراحة ولا ضمنًا.

\section{2- بالنسبة للمحتوى}

تضمن المحتوىن درسين من نماذج الأدب العربي في الحكمة بنسبة 5.5٪ أي بدرجة قليلة جدًا وبشكل صريح، وتضمن المحتوئ القيم الأخلاقية بنسبة 100٪. أي بدرجة كبيرة جدًا، وبشكل صريح وهذا من الجوانب المحمودة في المنهج حيث يتسق المحتون مع الأهداف بحيث يسهم في تحقيقها، في حين لمر تتناول موضوعات المحتون أبعاد الحكمة الأخرىن، وهي: التسامح، وقضايا عالمية معاصرة، و العو اطف الإنسانية المعقدة والمركبة، الحكمة ومكو ناتها وأهميتها، وأهمية التفكير التحليلي، ومشكلات مجتمعية محلية، ومراحل صنع القرار وأنواع القرارات، والتعاطف، ونسبية القيمة، ونماذج الحكمة العالمية، بأي نسبة علئ الإطلاق لا صراحة ولا ضمنًا، ولم تصاغ الدروس في شكل قضايا ومشكلات 


\section{3- بالنسبة للأنشطة}

اتضح من خلال التحليل أن أنشطة منهج اللغة العربية بالصف الأول الثانوي تضمنت من أبعاد الحكمة الأعحال التعاونية بدرجة كبيرة جدًا وبلغت النسبة 100٪ حيث اشتملت كل الدروس علن أنشطة ثنائية وجماعية وهذا من الجوانب الإيجابية المحمودة لواضعي المنهج في الأنشطة لأن التعاون من الأبعاد المهمة في الحكمة، ونشاط إجراء حوارات حول مشكلات واقعية بدرجة قليلة جدًا بنسبة 2.7٪، ونشاط إقامة مناظرات حول قضايا لغوية واجتماعية بدرجة قليلة جدًا وبنسبة 19.4٪؛ أما نشاط كتابة القصص بهص فقد ورد بنسبة 11.1\% أي بدرجة قليلة جدًا، وجمع الحكم والأمثال، والتحدث حول قضايا ومشكلات عالمية جاءت بدرجة قليلة جدًا بنسبة 5.5 ٪، ولم يرد نشاط كتابة المقالات، وأن تسهم الأنشطة في اتخاذ القرار لاصر احة ولاضمنًا.

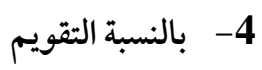
تضمن التقويم في منهج اللغة العربية للصف الأول الثانوي أسئلة تقيس بعض مهارات التفكير الإبداعي بدرجة قليلة جدًا بنسبة 38.8٪ وبشكل صريح، وأسئلة تقيس بعض مهارات التفكير

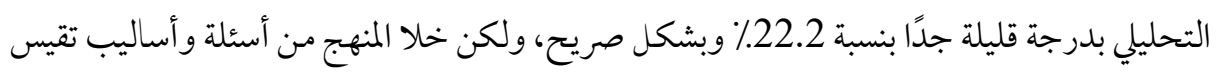
مهارات التفكير التأملي، وتتفق هذه النتيجة مع ما توصلت إليه دراسة (كامل،2013) من خلو

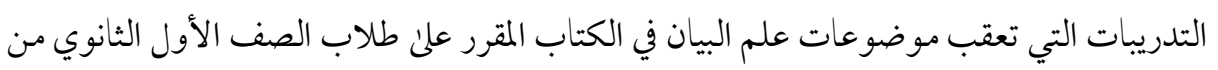
مهارات التفكير التأملي. كما خلت من أسئلة تقيس أبعاد الحكمة المتمثلة في مهارات صنع القرار، لئل ومهارات فهم الذات والتعبير عن المصالح الشخصية، ومهارات الذكاء العملي لتطبيق المعرفة اللغوية

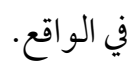
ثانيًا -نتائج تحليل منهج اللغة العربية للصف الثاني الثانوي تم حساب تكرار ظهور أبعاد الحكمة في منهج اللغة العربية بالصف الأول الثانوي أهدافه، ومحتواه، وأنشطته، وأسئلة التقويم به ونسبته المئوية فاتضح ما يبينه شكل (2) الآتي: 


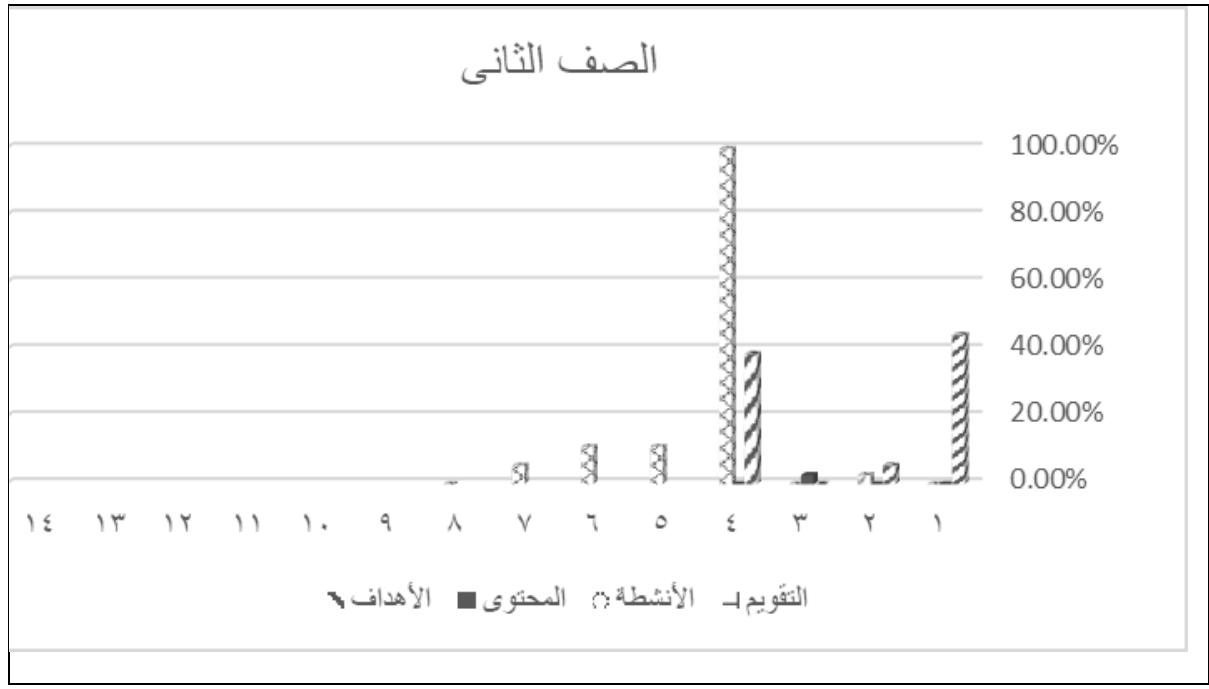

شكل (2)

\section{1- - بالنسبة للأهداف}

أ- نصت أهداف الدروس على تنمية القيم الأخلاقية بدرجة كبيرة جدًا بنسبة 100٪ حيث احتوئ كل درس علن قيمة أخلاقية معينة ومن هذه القيم: إعمال العقل، والصداقة، والعلم. وهذه من الجو انب الإيجابية في المنهج الحلالي، كما تضمنت أهداف الدروس تنمية بعض مهارات التفكير الإبداعي في منهج اللغة العربية بالصف الثاني الثانوي ولكن بدرجة قليلة جدًا بنسبة 44.4٪، وبشكل صريح، واقتصرت على مهارة الطلاقة لاقتراح العناوين والحلول، والتفكير التحليلي بدرجة قليلة بنسبة 55.5٪، واقتصرت علئ إبداء الر أي في المقروء حيث نصت علن إبداء الرأي في الصور الجمالية أو القضايا المعروضة في الدرس. واكتشاف التناقض، و التمييز بين الحقيقة والادعاء. ب- خلت أهداف منهج الصف الثاني الثانوي من أبعاد الحكمة الأخرىن حيث لم يسجل هل أي تكرار وهي: مهارات الذكاء العملي، ومهارات التفكير التأملي، وقبول الجوانب الإيجابية والسلبية للطبيعة البشرية، والتعاون، والتنظيم الانفعالي وتقبل الذات وفهمها، 
مراعاة التوازن بين المصالح الشخصية والعامة والتوجه نحو الصالح العام، ولمتعالجها

$$
\text { لا صر احة ولا ضمنًا. }
$$

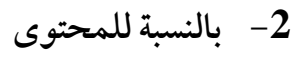

أ- تضمن المحتوكن دروسًا تتناول القيم الأخلاقية بدرجة كبيرة بنسبة 100٪ وهي أحدمكونات الحكمة الوجدًانية، كما وردت بعض الموضوعات بنسب ضعيفة مثل: نماذج من الأدب العربي الحكيمة في ثلاثة دروس بنسبة 8.3٪ أي بدرجة قليلة جدًا، ومشكلات مجتمعية محلية تمثلت

$$
\text { في درس واحد بنسبة 2.7\% أي بدرجة قليلة جدًا. }
$$

ب- لمر تحتو موضوعات المنهج على دروس تتصل مباشرة بالحكمة ومكوناتها و أهميتها، ولا بالموضوعات التي يمكن من خلالها مناقشة الحكمة والمهارات المرتبطة بها؛ حيث لم

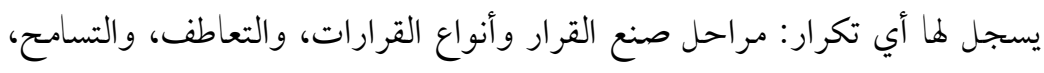
والعواطف الإنسانية المعقدة والمركبة، والقضايا العالمية المعاصرة، ونسبية القيمة حيث انعدم ظهور ها في المحتوىن، ولم تصاغ الدروس في شكل قضايا.

$$
\text { 3- بالنسبة للأنشطة }
$$

تضمن المنهج نشاط الأعمال التعاونية بدرجة كبيرة جدًا حيث بلغت النسبة 100٪ لاحتواء كل درس علن أكثر من نشاط جماعي وثنائي، وتضمن المنهج نشاط كتابة القصص بدرجة قليلة جدًا بنسبة 11.1٪ وبشكل صريح، كحا تضمن أنشطة: إقامة مناظرات حول قضايا لغوية واجتاعية. والتحدث حول قضايا عالمية ومشكلات محلية، ونشاط جمع الحكم والأمثال و كتابة مقالات بدرجة قليلة جدًا بنسبة 5.5\% لكل منها، وبشكل صريح؛ وتعد هذه النسب ضعيفة جدًا علن الرغم من أنها مهارات تعد تنميتها من أهم أهداف تدريس اللغة، وهي من الأنشطة المساعدة في تنمية الحكمة، وله تتضمن أنشطة المنهج ما يخص إجراء حوارات حول مشكلات واقعية لا صراحة ولا ضمنا، ولر تتسم الأنشطة بأنها تسهم في اتخاذ القرار. 


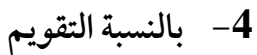

بعض الأسئلة تقيس مهارتين من المهارات المتطلبة للحكمة، وهي: مهارات التفكير التحليلي

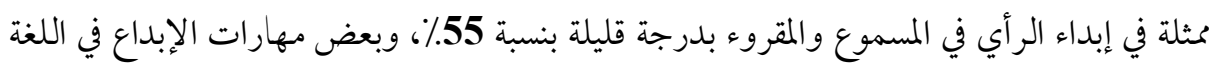

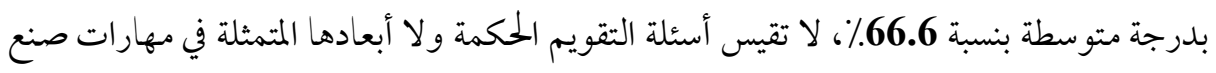

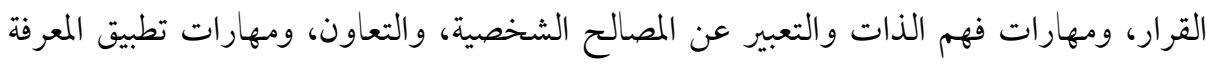
اللغوية في الواقع، ومهارات التفكير التأملي.

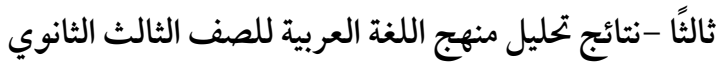
تبين من خلال تطبيق بطاقة تحليل مكونات منهج اللغة العربية للصف الثالث الثان الثانوي، ويوضح

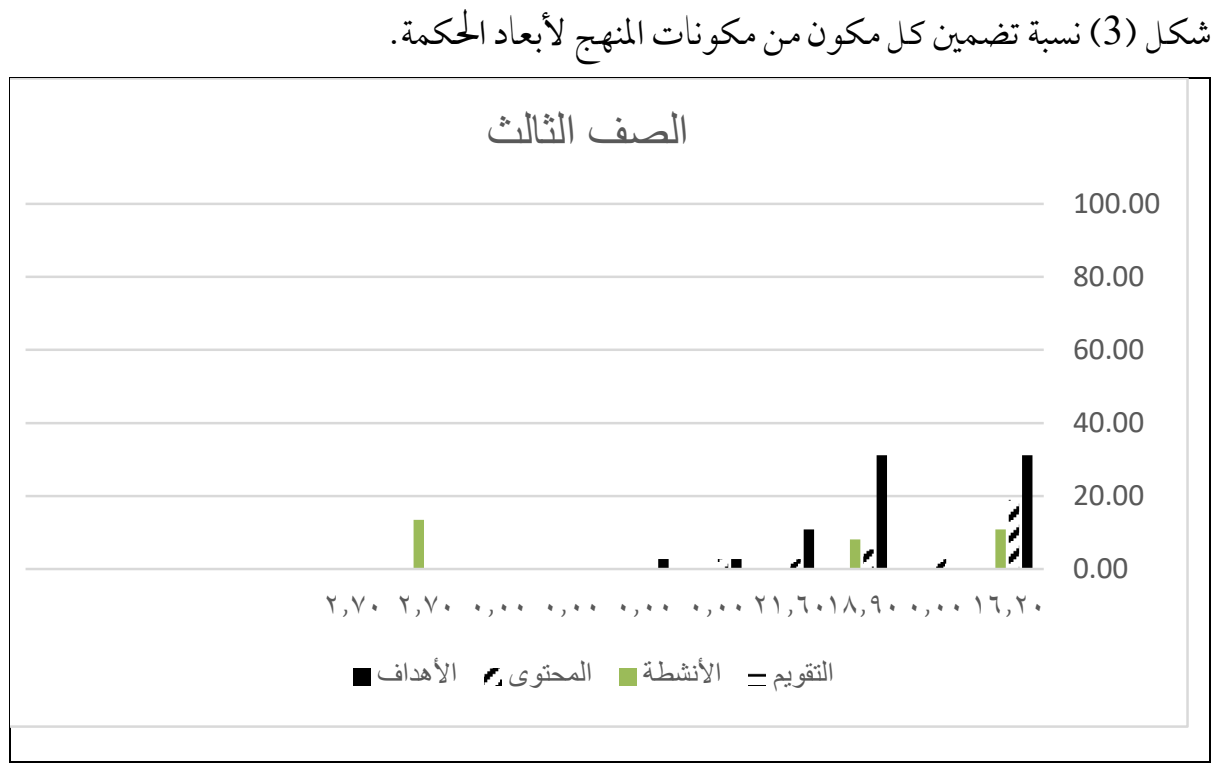

شكل (3)

http://dx.doi.org/10.29009/ijres.3.3.8 


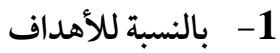

أ- نصت بعض أهداف منهج اللغة العربية للصف الثالث الثانوي على تنمية بعض مهارات التفكير التحليلي ومنها القدرة علن إبداء الر أي بدرجة قليلة جدًا بنسبة 21,6 ٪ وبشكل صريح، ومهار ات التفكير الإبداعي بدرجة قليلة جدًا بنسبة 16,2٪ واقتصرت علن تنمية مهار ات الطلاقة فقط باقتراح أكبر عددمن الكلمات أو العناوين، وتنمية القيم الأخلاقية بدرجة قليلة جدًا بنسبة 18,9 ٪. ب- تنمية مهارات التفكير التأملي والعملي لمرينص عليها صر احة ولا ضمنا في أهداف منهج اللغة العربية للصف الثالث الثانوي وكذلك قبول الجلوانب الإيجابية والسلبية للطبيعة البشرية، والتعاون، واتخاذ القرار، والتنظيم الانفعالي وتقبل الذات وفهمها، ومراعاة التوازن بين المصالح الشخصية والعامة والتوجه نحو الصالح العام؛ حيث لم يسجل هلا

$$
\text { أي تكرار. }
$$

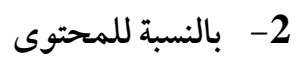

أ-ظهرت بعض الموضوعات التي تسهم في تنمية الحكمة بتكرار ضعيف ونسب مئوية منخفضة، وهي: نهاذج من الأدب العربي الحكيمة والقيم الأخلاقية بنسبة 31.13٪ لكل منها بدرجة قليلة جدًا، والتسامح بنسبة 10,8٪ بدرجة قليلة جدًا، وقضايا عالمية معاصرة، والعواطف الإنسانية المعقدة و المركبة بنسبة 2,7٪ بدرجة قليلة جدًا لكل منها حيث وردت في ثنايا تدريبات النحو كقطعة للتدريب علن ظواهر نحوية وإملائية وليس الغرض منها الالتفات إلى الموضوع أو قراءته كجانب معرفي. ب-لم تحتو مو ضو عات المنهج على دروس تتصل مباشرة بالحكمة ومكوناتها و أهميتها، ولا بالموضو عات

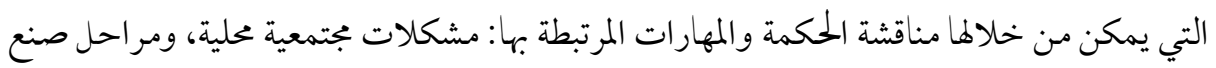
القرار وأنواع القرارات، والتعاطف، ونسبية القيمة حيث انعدم ظهورها في المحتوى؛؛ حيث لم يسجل ها أي تكرار. وله تصاغ الدروس في شكل قضايا أو مشكلات تاريخية. 


\section{3- 3 - بالنسبة للأنشطة}

أ- جاء نشاط كتابة المقال بدرجة قليلة جدًا 9،18 ٪ ولكن حول موضوعات غير جدلية إنما موضوعات تقليدية، وهي: أشهر العلماء العرب، وأثر العرب في الحضارة الأوروبية، والبحث العلمي، وحقوق الإنسان في الإسلام، والإسلام دين السلام، وحب الوطن، وأحد المعلمين أو العلم)ء المصريين. ب- نشاط إجراء الحوارات حول مشكلات واقعية، والتحدث حول مشكلات واقعية، والأعمال التعاونية ورد كل منهها مرة واحدة بنسبة 2.7 وبدرجة قليلة جدًا؛ علن الرغم من أنها مهارات تعد تنميتها من أهم أهداف تدريس اللغة، وكتابة القصص ورد بنسبة 5.5 و وهي درجة قليلة جدا. نشاط إقامة المناظرات حول قضايا لغوية أو اجتماعية ورد مرتين بنسبة 5.4 ٪ بدرجة

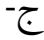
قليلة جدًا لا تمكن المتعلم من إتقان المهارات المتضمنة في المناظرة وتطلبت المناظرة:

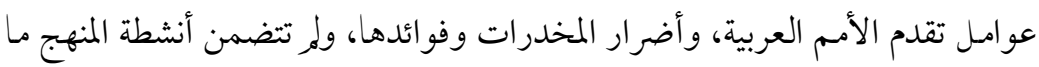
يخص جمع الحكم والأمثال أو أن تسهم الأنشطة في اتخاذ القرار.

$$
\text { 4- - - - بالنسبة للتقويم }
$$

تقيس بعض أسئلة التقويم في منهج اللغة العربية للصف الثالث الثانوي مهارات التفكير التحليلي ومنها: إبداء الرأي في المسموع والمقروء والنقد بنسبة 13.5٪ بدرجة قليلة جدًا، وبعض مهارات الإبداع في اللغة بنسبة 10.8٪ بدرجة قليلة جدًا، وتقيس مهارات التفكير التأملي بنسبة 8.1٪؛ كما أنها لا تقيس مهارات التفكير العملي ولا أبعاد الحكمة المتمثلة في مهارات صنع القرار، ومهارات فهم الذات والتعبير عن المصالح الشخصية، والتعاون. وبهذا تمت الإجابة عن السؤ الين الثاني والثالث من أسئلة البحث. 


\section{تعليق على نتائج تحليل منهج الصفوف الثلاثة:}

إن التضمين الصريح لأبعاد الحكمة ومكونات كل منها يفيد كلا من المعلم و المتعلم، فبالنسبة لتصلية للمعلم فإن التضمين الصريح يجعله يتحرى المهارات في تحضيره الدروس؛ فتظهر في أهدافه ويحاول اختيار طريقة لتدريسها، ويراعيها في الأمثلة التي يعرضها علن طلابه، ويقترح علن أساسها الأنشطة التي ينفذها معهم، كما تظهر في الواجبات التي يكلف طلابه بها في نهاية كل درس ـوفي أثناء تنفيذ درسه، و كذلك عند تقويم درسه تكون محور اللأسئلة التي يطر حها عليهم. وبالنسبة للمتعلم فإنه عندما يتعرف المهارات صريحة يحاول اكتسابها، والتركيز عليها ويبذل جهدًا في إجابة الأسئلة التي تقيسها؛ فالطلاب في المرحلة الثانوية حريصون علن بذل الجهد للحصول على الدرجات المرتفعة أملاًا في الالتحاق بالكليات التي يرغبونها.

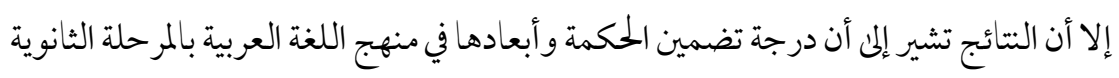
بصفوفها الثلاثة قليلة جدًا، وبخاصة مهارات التفكير الإبداعي واقتصرت علن "اقتراح عناوين

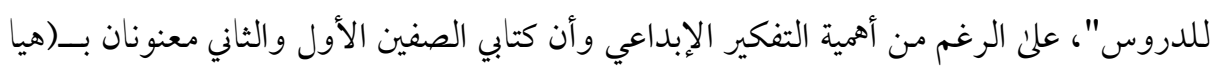

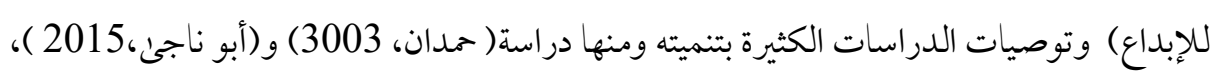
و(الشورى،2013)

وتتفق هذه النتيجة مع نتائج عدد من الدراسات التي تناولت القراءة والأدب و البلاغة بالمرحلة

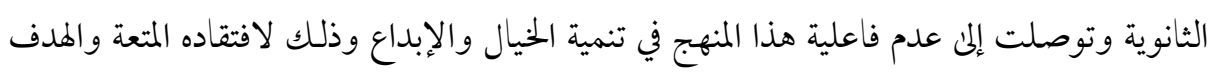
و القيمة، وتصميمه بطريقة جافة وفرضه على الطلاب نصوصا مقدسة لا تقبل النقد أو الزيادة أو النقصان، وعدم تصميمه في شكل مشكلات مؤرقة، كما أن منهج الأدب و النصوص غير كاف لتنمية حواس الطلاب الفنية وملكاتهم الأدبية، ومنهج البلاغة الذي يعرض المصطلحات عرضا جافا، ولا

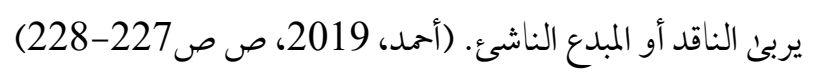

واتتئ التقويم معاكسًا لتوصيات كثير من الدراسات ومنها دراسة بدر (2010) الذي أكد أندات

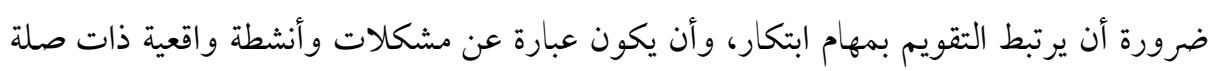


بشئون الحياة الواقعية، وتقويم ذاتي، وتقويم للأداء. وعلن الرغم من أن تشجيع الطلاب علن تطبيق ما عرفو اواستخدامه وممارسته وتوظيفه من أهم الممارسات التي تجعل التدريس يرتبط بحاجات التلاميذ الفعلية، وليس فقط بجرد ما يكون عمليًا لأفراد دون غيرهم مثال استخدام المعرفة عن لغة معينة لإنتاج

جمل جديدة. (Sternberg,2009)

تتفق هذه النتائج مع ما توصلت إليه دراسة السبع والفصلي (2015) التي كشفت أن كتب

القر اءة المقررة على طلبة المرحلة الثانوية بحاجة إلى إعادة تخطيط لتشمل جميع القيم في خختلف المجالات. وقد يرجع هذا المى أن مفهوم الحكمة وأبعادها حديث نسبياً عند غخططي المناهج، وتركيز الاهتمام على تعليم الطالب مهار ات اللغة بصفة عامة: القراءة والكتابة والتحدث والاستماع، وبشكل عام تشير نتائج التحليل إلى تدني درجة تضمين منهج اللغة العربية بالمرحلة الثانوية للحكمة والمهارات اللازمة لها بالرغم من أهميتها للربط بين ما يتعلمه الطالب وحياته بشكل عام ولإعداد مواطن قادر علئ التعامل بأسلوب سليم وناجح مع ما يعترضه من مواقف في حياته المستقبلية. للإجابة عن السؤال الرابع: ما الأسس اللازمة لتطوير منهج اللغة العربية وفق أبعاد الحكمة؟ قامت

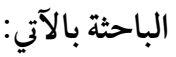

- - الاستفادة مما تم التوصل إليه في الخطوة السابقة من أبعاد الحكمة في صياغة قائمة مبدئية لأسس تطوير منهج اللغة العربية بتفصيل الأبعاد إلى مهار اتها الفرعية المكونة لها من خلال الاطلاع على الأدبيات و الدراسات السابقة، والاطلاع على مو اصفات الأهداف، و المحتوىن،

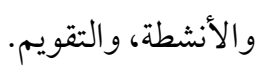

- - مياغة مبادئ عملية يمكن تطبيقها في صياغة الأهداف وتضمين أبعاد الحكمة خلالها، وفن اختيار موضوعات المحتوكئوطريقة تقديمها، واختيار الأنشطة وبناء أساليب التقويم. - عرض القائمة علن مجموعة من المحكمين للتأكد من صحة استخلاصها، وقد تم تعديلها في ضوء ملاحظاتهم ومن ثم التوصل إلى قائمة تضم اثنين وستين مبدًا قسمت إلى أربعة بجالات الأول: الأهداف وتضمن سبعة وعشرين بندا والمجال الثاني المحتوئ، وتضمن أحد عشر 
بندًا، والمجال الثالث الأنشطة وتضمن ثمانية بنود، و المجال الرابع التقويم، وتضمن ستة عشر . بندًا، يوضحها جدول (7) الآتي:

جدول (7) أسس تطوير منهج اللغة العربية وفق أبعاد الحكمة

\section{الأهداف}

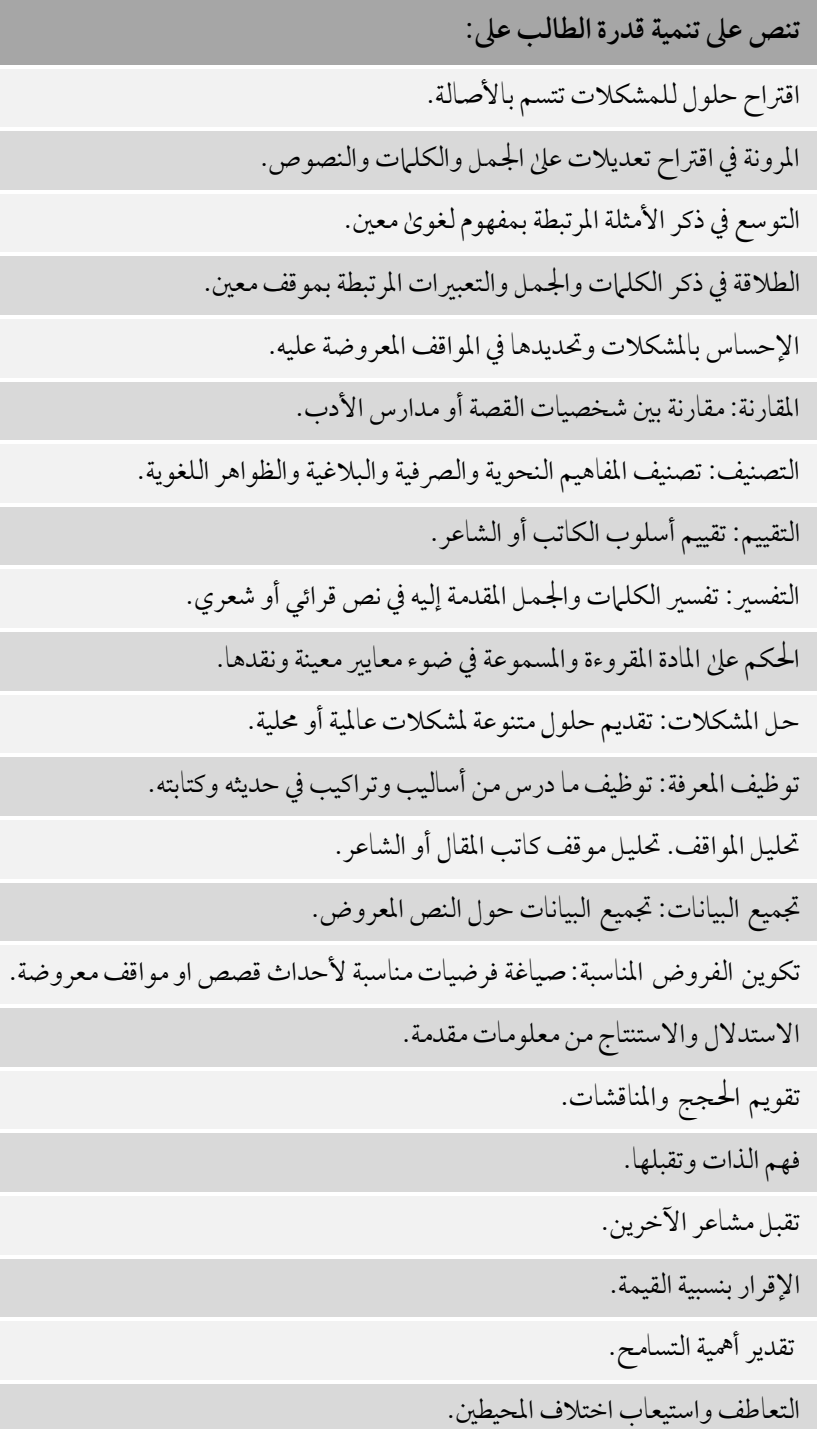

http://dx.doi.org/10.29009/ijres.3.3.8 
Volume (3) No. (3) 2020

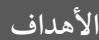

$$
\begin{aligned}
& \text { الإقرار بالغموض والشك في مو اقف الحياة والتعامل بإيجابية. } \\
& \text { تقدير أهمية التعاون. }
\end{aligned}
$$

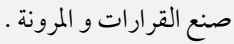

$$
\begin{aligned}
& \text { مر اعاة التوازن بين المصالح الشخصية والعامة والتوجه نحو الصالح العام. } \\
& \text { التعامل مع الآخرين مع مر اعاة السياق الثقافي. } \\
& \text { ثانيا المحتوى: يشمل المحتوى دروسًا تتناول } \\
& \text { قضايا ومشكلات دولية معاصرة. } \\
& \text { مشكلات بجتمعية محلية. } \\
& \text { قصص خيالية وأساطير من التراث. } \\
& \text { الحكمة ومكوناتها وأهميتها. } \\
& \text { سير ذاتية لزعماء وحكماء في وقت تاريخي معين. } \\
& \text { العو اطف الإنسانية المعقدة والمركبة. } \\
& \text { فهم حقائق الحياة والموت. } \\
& \text { مراحل صنع القرار وأنواع القرارات. } \\
& \text { حروب تاريخية. } \\
& \text { نهاذج من الأدب العربي الحكيمة. }
\end{aligned}
$$

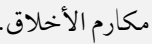

ثالثا الأنشطة: تتسم الأنشطة بأنها

تعتمد الأنشطة على الروح التعاونية، من خلال مشاركة الطلاب لـ

$$
\text { اتصالية تعتمد علئ مهارات الاتصال اللغوي. }
$$

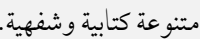

مثيرة للتفكير التحليلي: كتابة مقال تحليلي لمشكلة معينة وتقديم اقتراحات الحل. تعتمد على التفكير العملي وكتابة حلول عملية لمشكلات موجودة في الحياة. تتطلب التأمل الذاتي ووصف الخبرة الذاتية.

إبداعية إنتاجية تشمل كتابة القصص والمقالات الإبداعية كوصف الأشياء المثالية تعتمد علئ استخدام الإنترنت.

\section{http://dx.doi.org/10.29009/ijres.3.3.8}




\section{الأهداف}

ثالثا -التقويم: يتضمن أسئلة تقيس

فهم العلاقات بين الظواهر اللغوية أو الاجتماعية (تشابه، تضاد، تبعية ، إكمال، جزء ، مساواة ) تفسير أسباب سلوكيات معينة أو قصيدة أو خطبة أو مو اقف معقدة. قدرة الطالب علئ التوضيح والإفاضة. اقتراح حلول متعددة لمشكلات عالمية ومحلية. إعطاء الدليل على صحة مـا ذكر. تصنيف الظواهر اللغوية المختلفة. التنبؤ بالأحداث أو نتائج الأفعال المختلفة. تحديد العناصر المشتركة بين المفردات . استخراج الأخطاء الواردة في النص. توظيف المعرفة المتضمنة في المنهج في مو اقف جديدة. تحديد أوجه الشبه والاختلاف بين ظواهر الأدب واللغة. ترتيب الوقائع أو متطلبات مشروع أو المو اد في سياق معين. تحليل المشكلات والصراعات. تحديد المعايير المستخدمة للحكم أو الاختيـار أو القرار.

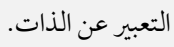

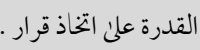

وبالتوصل إلى قائمة أسس تطوير منهج اللغة العربية وفق أبعاد الحكمة تمت الإجابة عن السؤال الرابع من أسئلة البحث.

للإجابة عن السؤال الخامس الذي نصه:" ما التصور المقترح لتطوير منهج اللغة العربية بالمرحلة الثانوية في ضوء أبعاد الحكمة؟" تم بناء تصور مقترح لتضمين أبعاد الحكمة في منهج اللغة العربية للمرحلة

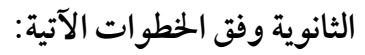


1- ت تحديد فلسفة التصور المقترح

$$
\text { يقوم التصور المقترح على: - ملن: }
$$

- توليف أبعاد الحكمة من عدة نماذج منها نظرية التوازن في الحكمة (2003.Sternberg)، ونموذج بالتر وستودنجر ( Stuadinger\& Baltes,2000)، ونموذج جرين ويرون (2009)، ونموذج أردلت حتى يمكن شمول أبعادها المختلفة، ودمج أبعاد الحكمة في كل مكونات المنهج. - - التدريب علن تحليل محتون الإنتاج الفكري الذي يتسم بالحكمة حيث يقال في الأثر:" إن كتابة المرء مرآة لعقله"؛ ومن ثمّ فإن تحليل محتوىن الإنتاج الفكري التراثي والمعاصر عبر الثقافات والأفراد، يزود الطلاب بتصورات حول خصائص الحكمة ومكوناتها، وكتب التراث اللغوي والأدبي زاخرة بكل أنواع النصوص التي يمكن لئن

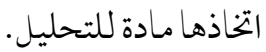
- - تنمية مهارات الاتصال: اللغة في أساسها أداة اتصال وتنمية المهارات الاتصاليـة من المهارات التي يجب أن يجوز الحكيم قدراً مرتفعاً منها؛ فالإنصات يعد بابًا أساسيًا للحصول علنى الخبرة من الآخرين، وتفهمهم، والتعاطف معهم، ومن ثمّ إسداء النصح والمشورة لهم، وكذلك فإن المحاجة تمكّن الفرد من أن يفهم ويكشف عن نقط الضعف في حجج الآخرين، وإقناعهم في المقابل بها يعتقد أنه مناسب؛ ومن ثمّ فهي من المقومات و الدعائم التي تقوم عليها الحكمة. - - العوامل الثقافيـة: التاريخ ومكونات الإرث الثقافي من الموضوعات التي تسهم في تنمية الحكمة، إن تاريخ الأمة وما يتضمنه من أحداث ونتاجها الثقافي وما يحتويه من أمثال، و أساطير، وأقو ال مأثورة يمكن أن يستخدم في المو اقف الحياتية المتنوعة سواء كانت عادية أو عصيبة على نحو يجعل سلوكهم فيها أكثر حكمة. 
- - - - - - - فالمنطق وسيلة مقننة لضبط الفكر والعقل، واللغة أداة التفكير فمن الضروري التدريب على مهار ات اللغة بمحتوكئ ينمئ التفكير المنطقي، فإن التدريب علن المنطق العقلي يجعل

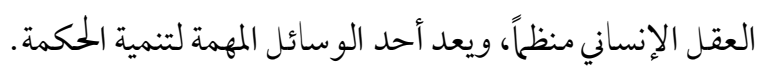

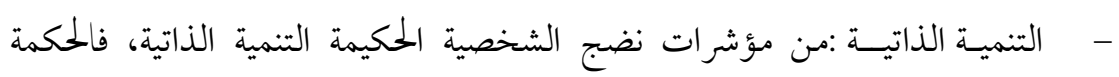
لا ترتقي فقط بالعمر ولكن بمحاولات التنمية الذاتية بها تحويه من عمليات كالوعي

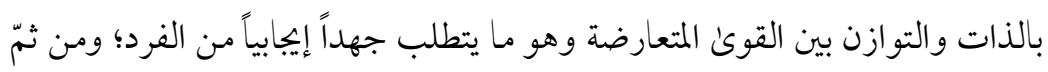
فإن استخدام وسائل التواصل الاجتحاعي الحديثة يمكن الطلاب من التنمية الذاتية

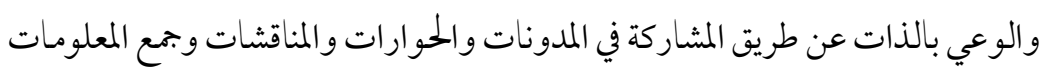
للتدليل علن صحة الر أي. أي. - - التأمل القائم على المحتوىن، حيث يتاح للطلاب التأمل في ضوء تجربة تعليمية خاصة، و التعبير عن تأملاتهم ومناقشتها.

2- تحديد نواتج التعلم المستهدفة: بالإضافة لأهداف منهج اللغة العربية الحالي فإن التصور المقترح يسعى إلى تحقيق أهداف رئيسية، وهي:

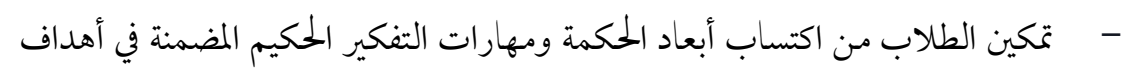
منهج اللغة العربية ومحتواه، وأنشطته.

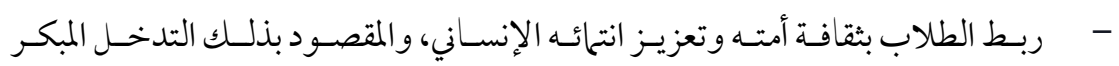

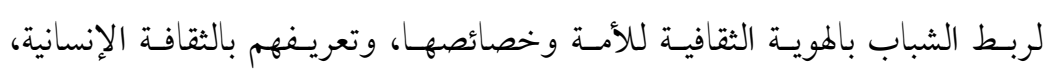

$$
\text { والتنـوع الثقافي والهويـة والوطنية. }
$$

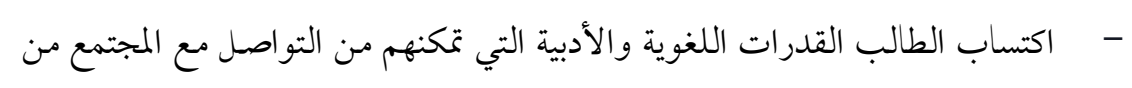

$$
\text { حوفم بكفاءة }
$$

- تنمية مهارات التفكير وتشجيع الطلاب علن الإبداع والابتكار . . 


$$
\text { - - - تدريب الطلاب على مهارات التخطيط والإدارة والقيادة في إطار مجتمعي . }
$$

- - تنمية وعئ الطلاب بالبعد الجغر افي لوطنهم وعلاقته بالمحيط الجغر افي العالمي من حوهم.

$$
\text { - - - تنمية الحس اللغوي لدئ الطلاب وتشجيع الموهبة والإبداع اللغوي لديهم. }
$$

ويندرج تحتها عدة نواتج تتعلق بتنمية مهارات التفكير المتعلق بالحكمة وهو التحليلي والتأملي والعملي

$$
\text { والإبداعي ودججها مع مهارات اللغة، وقد تم تفصيلها في الدروس المختلفة. }
$$

$$
\text { 3- ت تحديد المحتوى والموضوعات المقترحة }
$$

- - تم اقتراح 100 موضوع لكل صف دراسي، بعضها من التراث وبعضها الآخر من

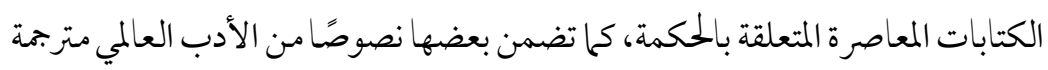

$$
\text { للقر اءة والتحليل. }
$$

- - تنوعت الموضوعات بين نصوص قرآنية، وأحاديث نبوية شريفة، وقصص، وخطب، و أشعار ومقالات، واختيرت القاعدة النحوية والجنس البلاغي وفق الشواهد الموجودة

$$
\text { في كل نص حتى يتحقق تكامل فنون اللغة. }
$$

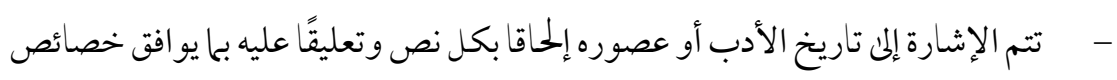
المرحلة التاريخية وكما يظهر في طريقة عرض النص حيث تناقش الظروف السياسية

$$
\text { والاقتصادية للعصر الذي أنتج فيه النص. }
$$

- - مم مراعاة التكامل مع منهج التاريخ في ترتيب الدروس بحيث يتناول المنهج في الصف الأول الثانوي نصوصًا من العصر الفرعوني وحضارة بابل والحضارة اليونانية والرومانية، وفن الصف الثاني الثانوي يتضمن المحتون نصوصًا من العصر الجاهلي

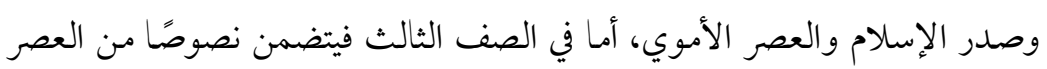

$$
\text { العباسي والحديث ونماذج من الأدب العالمي. }
$$

\section{http://dx.doi.org/10.29009/ijres.3.3.8}


- يتم تدريس قواعد اللغة العربية والبلاغة في هذه المرحلة من منطلق التعامل الوظيفي في

$$
\text { النص أو السياق، توظيف القو اعد لا حفظها. }
$$

- - تم تقسيم المحتوى في كل صف إلى ثلاث وحدات الأولى تدور حول الحكمة، والوحدة الثانية تدور حول المهارات الحياتية أمسا الثالثة فتتناول دروسها مشكلات وقضايا عالمية

$$
\text { ومحلية، وتحتوي كل منها علن ثلاثة دروس. }
$$

- وزعت الموضوعات علن سنوات الدراسة الثلاث بواقع ثلاث وحدات في الفصل

$$
\text { الدراسي الأول وثلاث في الفصل الدراسي الثاني. }
$$

- - يتم تقديم المحتوكن بطريقة اختيارية دون التقيد بكتاب المدرسة كما يمكن الاستغناء عن طباعة الكتاب المدرسي بأن تتاح النصوص الثلاثة المرتبطة بكل درس ليختار منها المعلم

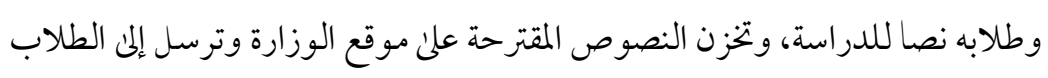
عبر البريد الإلكتروني ليتم قراءتها قبل الحصة واختيار النص الذي يرغبون في دراسته، ونها،

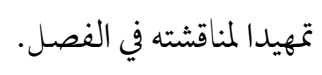

4- تحديد الأنشطة: تم اقتراح بجموعة من الأنشطة التي يمكن أن تسهم في تنمية الحكمة وأبعادها المختلفة، ووزعت على سنوات الدراسة الثلاث بواقع نشاطين لكل درس في كل صف دراسي، وتم ترتيب الأنشطة وفق ما توصلت إليه أبحاث تنمية التفكير وترتيب مهاراته

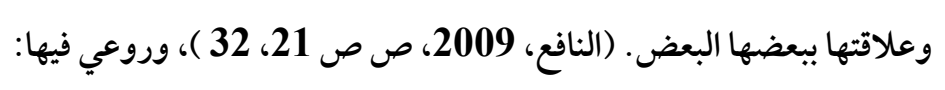

$$
\text { - - - التنوع ما بين شفهية وكتابية. }
$$

- - متعمد علن البحث عن المعلومات و المناقشة.

- - ميتم تنفيذ بعض الأنشطة باستخدام تطبيقات الإنترنت المختلفة: المدونات للكتابة،

$$
\text { والبودكاست لأنشطة الاستماع، والمنتدى للمناقشة غير التزامنية. }
$$

- - يتم تنفيذ بعض الأشطة في الفصل ومنها: التمثيل، والحكي، والمناظرة، و إلقاء الشعر. 
وكانت كالآتي:

أ- أنشطة بحث وجمع معلومات وتتضمن: جمع معلومات وأشعار وحكم وأمثال. ب- أنشطة كتابة وتشمل : كتابة مقال، وكتابة قصة، وكتابة تقرير، وسيرة ذاتية، وتعليق على رسوم كاريكاتورية، وتصميم لاقتات تحذيرية وإرشادية.

أنشطة شفهية وتتضمن: التحدث، وإلقاء الشعر، والخطبة، وإدارة حوار والتمثيل، والمناظرة،

والحكي.

$$
\text { 5- ت تحديد الزمن اللازم للتدريس }
$$

يستغرق تدريسه الوقت نفسه اللازم لتدريس المنهج الحالي 27 حصة في الفصل الدراسي و54 حصة على مدار العام الدراسي كاملًا.

$$
\text { 6- ت تحديد أساليب التقويم }
$$

تستخدم أساليب التقويم التي تقيس العائد المجتمعي والحياتي من تعلم اللغة، وتتسم بالآتي:

السماح بتقويم متوازن بين الاختبارات الموضوعية عالية الجودة، وأدوات التقويم البنائي والجمعي؛ والتوزان بين التقويم البنائي والجمعي واستخدام التكنولوجيا في التقويم باستخدام الاختبارات

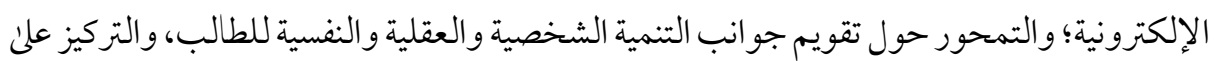
التغذية الراجعة اليومية الأداء الطالب في التعلم اليومي؛ واستخدام ملفات الإنجاز، وتشجيع تقويم المشروعات، وير اعىى أن تخصص درجة علن الاستجابة المتسمة بالحكمة إضافة المي الدرجة المخصصة لقياس الظاهرة اللغوية، والاعتهاد على قو ائم تقييم ذاتي يستخدمها الطالب لتقييم ذاته. كما تستخدم صيغ الأسئلة التي تقيس الحكمة وأبعادها المختلفة تمثلت هذه الأسئلة في: أ- أ-مشكلات حياتية ويتعين علن الطالب اقتراح حلول مناسبة متضمنة أساليب وتراكيب لغوية معينة. ب- ب-حلول لمشكلات عالمية ومحلية ويتعين علن الطالب نقد الحلول وتقييمها في ضوء معايير التفكير الحكيم. 
7- التحقق من ملاءمة التصور المقترح

تم عرض التصور المقترح على نخبة من أعضاء هيئة التدريس تخصص المناهج وطرق تدريس اللغة العربية، وبجموعة من موجهي اللغة العربية؛ للتأكد من مناسبته للطلاب، وتناسق الأهداف والمحتوى و الأنشطة وأساليب التقويم، ويعد تلقى ملاحظاتهم و التعديل في ضوئها، تم اعتماد التصور في صورته النهائية ملحق (7) وبهذا تمت الإجابة عن السؤال الخامس من أسئلة البحث.

التوصيات

في ضوء ما تم عرضه من نتائج يوصى البحث بالآتي:

وضع سياسات عامة لتطوير مناهج دراسية تتضمن أنشطة قائمة على الحكمة لتنمية قدرة

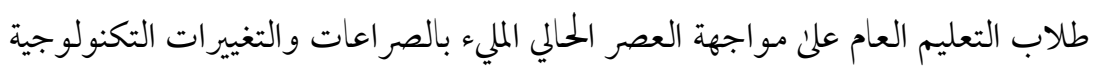
والثقافية والقيمية.

تدريب معلمي التعليم العام في جميع المراحل التعليمية: ابتدائي، وإعدادي، وثانوي علن

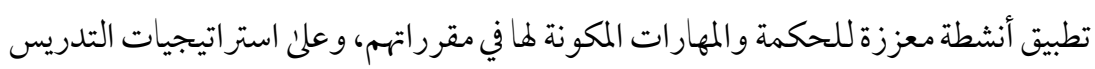

$$
\text { التي تسهم في تسهيل الأداء المتعلق بالحكمة. }
$$

تدريب الطلاب على كتابة المقالات وإجر اء المناظرات وتشجيعهم علئ مناقشة المشكلات

والقضايا باستخدام التفكير التأملي، والتفكير التحليلي، و التفكير العملي.

اختيار موضوعات القراءة والأدب من الكتب التي تعرض حكمة الحكماء، سو اء كتب تراثية أو معاصرة عربية أو مترجة، وعرض أمثلة للحكمة، وكيف يمكن تطبيق الحكمة في حياة

$$
\text { الطلاب و العاله الحلالي. }
$$

توضيح السياق التاريخي الاجتحاعي للنصوص المعروضة حتى يمكن فهمها في ضو همطيات عصرها.

التقويم باستخدام حل المشكلات وحل الصراع بحيث يخصص جزء من درجة التقويم للكفاءة اللغوية وجزء لجلودة هذه الاستجابات لمعرفة ما إذا كانت تعكس قرار المبندات حكيمة. تدريب الطلاب المعلمين بكليات التربية على التدريس من أجل الحكمة. 


$$
\text { في ضوء ما توصل إليه البحث يقترح إجراء الأبحاث الآتية: }
$$

- - دراسة تكاملية بين العلوم والتاريخ واللغة العربية لتضمين الحكمة عبر مناهج المرحلة

$$
\text { الثانوية. }
$$

- - تحليل كتب التراث التي تناولت الحكمة لاشتقاق محتوئ لكتب اللغة العربية في مراحل

$$
\text { التعليم المختلفة. }
$$

- - تقويم مدئ تضمين مناهج اللغة العربية في التعليم الأساسي لأبعاد الحكمة. - - فاعلية برنامج لتدريب معلمي اللغة العربية على تطبيق التدريس من أجل الحكمة. - دراسة فاعلية بناء برنامج لتدريب الطالب المعلم علن التدريس من أجل الحكمة. 
1. ابن منظور، لسان العرب، (1981).

2. أبو مصطفى ، يونس إبراهيم .(2017)" فلسفة الحكمة والفخر في شعر مسكين الد ارمي، بجلة

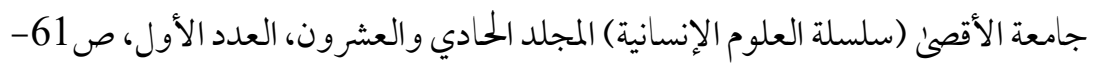
89

3. أبو ناجئ، شياء محمود سيد .( 2015).فاعلية نموذج تدريسي في اللغة العربية قائم علن التعلم المستند إلى الدماغ في تنمية مهارات الإبداع اللغوي والدافعية للإنجاز لدئ طلاب المرحلة

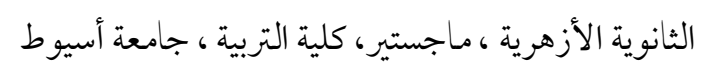

4. أحمد، سمير عبد الوهاب.(2019).مناهج اللغة العربية في المرحلة الثانوية وتنمية الخيال والإبداع تساؤل وطموح، المؤتمر العلمي الدولي السادس، السابع والعشرون للجمعية المصرية للمناهج وطرق التدريس، توجهات مستقبلية في المناهج و التدريس، دار الضيافة ، جامعة عين شمس،24-25 يوليو 2019.

5. البخاري، كتاب العلم، باب الاغتباط في العلم والحكمة، (73). 6. بدر، بثينة محمد.(2010). الاتجاهات الحديثة في تقويم المعرفة الرياضية، بجلة التربية

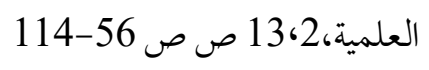
7. البوغبيش، عواطف.(2012). الحكمة ومصادرها في العصر العباسي، ديوان العرب، متاح علن: : http://www.diwanalarab.com/spip.php?article32904\#.XIa5KijXJPY آخر

$$
\text { زيارة : } 2017 / 5
$$

8. جاكاريجا كيتا، و إسماعيل محمد زيد.( 2017)، المو اصفات المعيارية مدخل لتطوير منهج قواعد اللغة العربية في ضوء معايير الجلودة، بجلة جيل العلوم الإنسانية والاجتماعية، العدد 35 
9. الجمفري، رياض بن عبد الرحمن، (2014)، تقويم محتوى مقررات المطالعة في المرحلة الثانوية بالمملكة العربية السعودية في ضوء قضايا المجتمع المعاصرة ـ المجلة الدولية التربوية المتخصصة، بجلد3، العدد 11

10 الجوزية، ابن قيم،( 2003)، مدارج السالكين (ت. البغدادي)، دار الكتاب العربي 11. حسين، شلوف.(2006). شعر الحكمة عند المتنبي بين النزعة العقلية والمتطلبات الفنية، رسالة ماجستير، كلية الآداب واللغات، جامعة منثوري، الجزائر. 12.حمدان، سيد السايح. (2003) . استخدام أسلوب العصف الذهني في تدريس البلاغة وأثره في تنمية التفكير الإبداعي والكتابة الإبداعية لدىن طالب المرحلة الثانوية، الجمعية المصرية للمناهج وطرق التدريس، المؤتمر العلمي الحنامس عشر، مناهج التعليم والاعداد للحياة المعاصرة، جمع.

13. خضير، إسراء نذير.(2018).الحكمة في الشعر الجاهلن،كلية التربية، جامعة القادسية. متاح

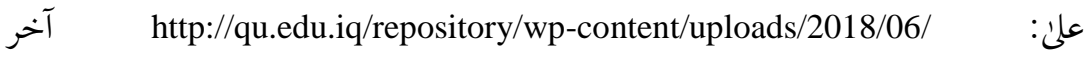
زيارة:2019/3/

14 ـدجاكاريدجا، كيتا. (2017) . واقع تطوير منهج قو اعد اللغة العربية للمرحلة الثانوية بالمدارس العربية في مالي في ضوء المو اصفات المعيارية صفات المعيارية المعيارية، مجلة والنفسية التربوية الدراسات التربوية المجلد1 العدد 2ججلة الدراسات التربوية والنفسية - جامعة السلطان

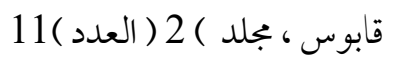

15.الدوسري، ماجد بن مرزوق بن عبدالله.(2008). الحكمة في شعر شوقي (المضامين و التشكيل)، رسالة ماجستير، كلية اللغة العربية، جامعة أم القرىن.

16.السبع سعاد سالم، الفصلي، محمود صغير.(2015). مدئ توافر القيم اللازمة لطلبة المرحلة الثانوية في كتب القراءة، بجلة جامعة الناصر، العدد الخامس المجلد الثاني يناير -يونيو 
17 السيد محمد شفيع الدين، (2016) نحو منهج مقترح لدراسة العربية في مرحلة التعليم الثانوي، مؤتمر مجمع اللغة العربية بالقاهرة في دورته الثانية والثهانين، "واقع اللغة العربية في المجتمعات العربية: الأسباب والمواجهة مجمع اللغة العربية، القاهرة.." 18.شاهين، جودة.(2010).التنبؤ بالذكاء الشخصي من التوافق الدراسي واتخاذ القرار لدىن عينة من طالبات كلية التربية بالمملكة العربية السعودية، دراسات نفسية، مجلد20، عدد2، إبريل.

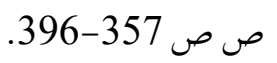

19. الشريدة محمد خليفة ناصر، والجراح عبد الناصر ذياب، وبشارة موفق سليم. (2013). القدرة التنبئوية للذكاءات المتعددة بمستوئ الحكمة لدئ الطليبة الجامعيين في الأردن، بجلة اتحاد الجامعات العربية للتربية وعلم النفس، المجلد الحادي عشر، العدد الأول، ص ص 110-

20. الشريدة محمد، والجر اح عبد الناصر، وبشارة موفق. (2013). القدرة التبوئية للذكاءات المتعددة بمستوئ الحكمة لدئ الطلبة الجامعيين في الأردن، بجلة اتحاد الجامعات العربية للتربية وعلم

$$
\text { (1) النفس، 11) } 11 \text { (1) }
$$

21. الشريدة، محمد، و خليفة ناصر.(2015). مستوئ التفكير ما وراء المعرفي والحكمة لدىن عينة من طلبة الجامعة والعلاقة بينها، المجلة الأردنية في العلوم التربوية، مجلد 11، عدد4، 403

415 -

22. الشورة، غادة خالد. (2013). درجة تطبيق مهارتي المرونة والتوضيح في تدريس اللغة العربية وأثره في التحصيل والذكاء اللغوي لطالبات الصف التاسع الأساسي في لواء ذيبان الأردن، ماجستير، كلية العلوم التربوية جامعة الشرق الأوسط.

23.طعيمة، رشدي أحمد.(2004). تحليل المحتوئ في العلوم الإنسانية (مفهومه - اسسه -

$$
\text { استخداماته)، دار الفكر العربي -القاهرة. }
$$

24.العاسمي رياض، 2014، الحكمة، المؤتمر الدولي للغة العربية، دبئ الإمارات، متاح 2018 / 2 / آخر زيارة: http://www.alarabiah.org/index.php 
25. عبد الجو ادو وفاء محمد. (2015). الحكمة وعلاقتها بمهارات التفاوض لدئ عينة من طلاب الدراسات العليا بالإرشاد النفسي والتربية الخاصة، مجلة التربية الخاصة، جامعة

$$
\text { الزقازيق،العدد12، ص ص 75-125. }
$$

26. عبد الفتاح، فاتن فاروق، حليم، شيري مسعد.(2014). الصمود النفيي لدئ طلبة الجامعة وعلاقته بكل من الحكمة وفاعلية الذات لديهه، بجلة كلية التربية جامعة بورسعيد، العدد15،

$$
\text { يناير }
$$

27. عبد المجيد، أسامة محمد. (2018). التَّربية بالحكمة: الدوافع والمكتسبات، موقع الرؤية العمانية، 7 فبراير، متاح على /https://alroya.om/post/207260 خر زيارة13/ 2028 28.العتباني طاهر.(2011). فلسفة الموت والحياة في معلقة طرفة بن العبد، مجلة الألوكة، https://www.alukah.net/literature_language/0/32147/\#ixzz5hsc2CzHm:متاح

$$
\text { آخر زيارة:2016/8/10 }
$$

29. غو ادرة، نضال . (2016). تقويم منهاج اللغة العربية الفلسطيني الجديد للصف العاشر الأساسي من وجهة نظر المعلمين والمعلمات في محافظة الخليل، مجلة كلية التربية الأساسية للعلوم

$$
\text { التربوية والإنسانية، العدد } 26 \text { جامعة بابل نيسان / 2016م لمعين }
$$

30.فاضل. رنا زهير محمد.( 2008).تطور الذكاء الأخلاقي لدى المراهقين، مجلة كلية الآداب

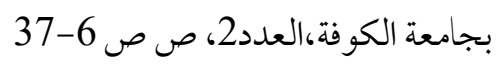

31. كامل، محمد أحمد. (2013).تقويم أسئلة البلاغة في ضوء مهارات التفكير التأملي للصف الأول

$$
\text { الثانوي ، بجلة كلية التربية جامعة بورسعيد، العدد الرابع عشر-يونيو }
$$

32. محمود، محمد عبد الرحمن.( 2014). شعر الحكمة والزهد في عصر الطوائف، مجلة كلية الإمـام

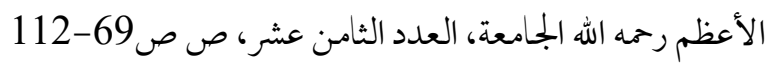

33. المسعودي، عحار. (2012). الحكمة في شعر الصعاليك (دراسة تحليلية)، مجلة آل البيت، العدد

$$
\text { الثاني عشر، مارس، ص ص 294-304. }
$$


34.منصور، سماح محمد محب عبده. (2014). تصور مقترح لتطوير منهج اللغة العربية في المرحلة الثانوية في مصر في ضوء نتائج البحوث التربوية وتوجهاتها المستقبلية من 2000 - 2011، رسالة دكتوراه، كلية الدراسات العليا للتربية، جامعة القاهرة

35. النافع، عبد الله.(2009).تعليم التفكير في العالر العربي خطة استراتيجية مقترحة، مركز ديبونو لتعليم التفكير. اللقاء العربي الثاني لتعليم التفكير وتنمية الإبداع، 23-24 تموز ، دار ديبونو للنشر والتوزيع عمان الأردن.

36.النووي أبو زكريا محيي الدين يميئ بن شرف (1392) المنهاج شرح صحيح مسلم بن الحجاج، دار إحياء التراث العربي، بيروت الطبعة :الثانية.

37.وزارة التخطيط. (2015). استراتيجية التنمية المستدامة رؤية مصر 2030(الأهداف ومؤشرات

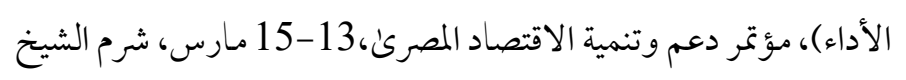

38. وزارة التربية والتعليم (2007 ). التعليم للجميع: تقرير متوسط المدىن 2000-2007، القاهرة المركز القومي للبحوث التربوية والتنمية.

39.الياسر، مصطفى نعيمس.(2011) تطور الحكمة في مرحلتي المراهقة والرشد ,أطروحة دكتوراه، جامعة بغداد، كلية التربية ابن رشد بغغداد 


\section{References}

- A, Law, \& U.M, Staudinger(2016). Wisdom, Encyclopedia of Mental Health, Volume 4 ,P.375-381.

- Abdel Fattah, Faten Farouk, Halim, Sherry Massad. (2014). Psychological resilience of university students and its relationship with both wisdom and self-efficacy, Journal of the Faculty of Education, Port Said University, No. 15, January

- $\quad$ Abdel Gawad Wafaa Mohamed. (2015). Wisdom and its relationship with the negotiation skills of a sample of graduate students psychological counseling and special education, Journal of Special Education, Zagazig University, No. 12, pp. 75-125.

- Abdul Majeed, Osama Mohammed. (2018). Education with Wisdom: Motivations and Acquisitions, Oman Vision, February 7, available at https://alroya.om/post/207260/ Last visit 13/2/2028

- $\quad$ Abu Mustafa, Younis Ibrahim. (2017) The Philosophy of Wisdom and Pride in the Poetry of Poor Poor Darmi, Al-Aqsa University Journal (Humanities Series) Volume XXI, Number 1, pp. 61-89, January

- $\quad$ Abu Naji, Shaimaa Mahmoud Sayed (2015). The Effectiveness of a Teaching Model in Arabic Language Based on Brain-based Learning in Developing Linguistic Creativity and Motivation Skills for Achievement among AlAzhar High School Students, MA, Faculty of Education, Assiut University

- $\quad$ Ahmed, Samir Abdel Wahab. (2019). Arabic language curricula in the secondary stage and the development of imagination and creativity question and ambition, the sixth international scientific conference, the twenty-seventh international Egyptian Association for Curriculum and Teaching Methods, future directions in curricula and teaching, the guest house, Ain Shams University, 24- 25 July 2019.

- Al Masoudi, Ammar. (2012). The Wisdom in the Poets of the Tramps (Analytical Study), Al-Bayt Magazine, No. 12, March, pp. 294-304. 
- Al Sabaa Suad Salem, Al-Fasly, Mahmoud Sagheer, (2015) Availability of Values for Secondary School Students in Reading Books, Al-Nasser University Journal, Volume 5, Volume 2, January-June

- Al-Assimi Riad, 2014, Wisdom, International Conference on Arabic Language, Dubai UAE, available http://www.alarabiah.org/index.php Last visit: $11 / 9 / 2018$

- Al-Bukhari, the book of science, chapter of exultation in science and wisdom, No. (73),

- $\quad$ Al-Dossary, Majed bin Marzouk bin Abdullah (2008). Wisdom in Shawki poetry (contents and composition), Master Thesis, Faculty of Arabic Language, Umm Al-Qura University.

- Al-Faouri, Oraib (2006). The impact of the Quart 4 program on creativity in developing critical reading among gifted and talented students. The First Arab Meeting of Court Experts: Amman

- Al-Jaafari, Riyad bin Abdul Rahman, (2014), Evaluation of the content of reading curricula in secondary school in Saudi Arabia in the light of contemporary society issues - International Journal of Specialized Education, Vol. 3, No. 11

- $\quad$ Al-Jawziyyah Ibn Qayyim, (2003), Runways of the Walkers (T. Baghdadi), Dar al-Kitab al-Arabi

- Al-Nafea, Abdullah (2009). Teaching Thinking in the Arab World: A Proposed Strategic Plan, Debono Center for Teaching Thinking. The Second Arab Meeting for Teaching Thinking and Developing Creativity, 23-24 July, Debono Publishing House Amman, Jordan.

- Al-Nawawi Abu Zakaria Mohiuddin Yahya Bin Sharaf (1392) Curriculum Explanation of Sahih Muslim Ibn Al-Hajjaj, House of Revival of Arab Heritage, Beirut Edition: Second.

- $\quad$ Al-Otaibi, Khalid Bin Nahis (2007). The Effect of Using Some Parts of the Kurt Program on Developing Critical Thinking Skills and Improving Academic Achievement among a Sample of Secondary School Students in Riyadh. 
- Al-Shraideh, Al-Jarrah Abdel-Nasser, and Bishara Mowaffaq (2013) The Predictive Ability of Multiple Intelligences at the Level of Wisdom among University Students in Jordan, Journal of the Federation of Arab Universities for Education and Psychology, 11, (1)

- Al-Sorour Nadia Hayel, (2008) Elements of the Interrelationship between Active Thinking and Creative Achievement, Second Arab Meeting for Teaching Thinking and Developing Creativity, Debono Center for Teaching Thinking, July 23-24.

- Alwan Ahmad Falah and Al-Ezzo, khtam (2007), the effectiveness of a training program for metacognitive skills on the development of critical thinking skills of university students, Journal of Educational Sciences, College of Education, Qatar University, p 13

- $\quad$ alyasir, mustafaa naeims . (2011) development of Wisdom in Adolescence and Adulthood, Ph.D. Thesis, University of Baghdad, College of Education, Ibn Rushd, Baghdad

- $\quad$ Ardelt, M. (2004). Wisdom as expert knowledge system: A critical review of a contemporary operationalizations of an ancient concept. Human Development, 47, 257-285.

- $\quad$ Ardelt, M. (2010). Are Older Adults wiser than College Students? A Comparison of Two Age Cohorts. Journal of Adult Development, 17(4), Dec 2010, 193 207.

- Atabani Taher. (2011). The Philosophy of Death and Life in Tarfa Bin Al-Abed Hanging, Alloka Magazine, Available at: https://www.alukah.net/literature_ language/0/32147/\#ixzz5hsc2CzHm Last visit: 10/8/2016

- Bader, Buthaina Mohammed. (2010). Modern Trends in Evaluating Mathematical Knowledge, Journal of Scientific Education, 13.2, pp. 56-114 - $\quad$ Baltes, P.B., Staudinger, U.M., 2000. Wisdom: A metaheuristic to orchestrate mind and virtue towards excellence. American Psychologist 55, 122-136. 
- Bang,H.(2009).The relationship of Wisdom and ego Identity for Korean and American Adolescents , unpublished dissertation, Oklahoma state university, USA,

- $\quad$ Bergsma ,Ad \& Ardelt Monika (2011) .Self-Reported Wisdom and Happiness: An Empirical Investigation, J Happiness Stud.

- $\quad$ Bluck, S., \& Glück, J. (2004). Making things better and learning a lesson: Experiencing wisdom across the lifespan. Journal of Personality, 72(3), 543572.

- Bogbish, Awatif . (2012). Wisdom and its sources in the Abbasid period, Diwan al-Arab, available at: http://www.diwanalarab.com/spip.php?article32904\#.XIa5KijXJPY

- Curnow, T. (2008). Sophia's world: Episodes from the history of wisdom. In M. Ferrari \& G. Potworowski (Eds.), Teaching for wisdom: Cross-cultural perspectives on fostering wisdom (pp. 1-19). Dordrecht, Netherlands: Springer.

- Djakaridja, Keita. (2017). The reality of developing the Arabic grammar curriculum for secondary schools in Arabic schools in Mali in the light of the standard specifications, The Soul : Journal of Human and Social Sciences Generation, No. 35

- $\quad$ Fadel. Rana Zuhair Mohammed (2008), The Development of Moral Intelligence in Adolescents, Journal of the Faculty of Arts, University of Kufa, No. 2, pp. 6-37

- Foucault, M. (2005). The hermeneutics of the subject: Lectures at the Collège de France,1981-1982. (G. Burchell, Trans.). New York: Palgrave-Macmillan.

- Gerver, R. (2010). Creating tomorrow's schools today. Education - our children - their futures. New York: Continuum International Publishing Group.

- Greene Jeffrey A., Brown Scott C.,(2009)The Wisdom Development Scale: Further Validity Investigations, The International Journal of Aging and Human Development, Vol. 68, Issue 4, pp. 289 - 320 
- Hamdan, Sayeh Sayeh. (2003). The use of brainstorming method in teaching rhetoric and its impact on the development of creative thinking and creative writing for secondary school student, Egyptian Association for Curriculum and Instruction, 15th Scientific Conference, Curricula and preparation for contemporary life, part 2,

- $\quad H U ̈ S E Y I N$, Ahmed Seyid \& ElAbdulhadi TIMURTAŞ, The Wisdom, in Arabic Poetry, The Non-Poem of Abu al-Fath al-Basti as a Model, Journal of the University College of Theology,pp38-62 http://isamveri.org/pdfdrg/_HUSEYINAS_TIMURASA.pdf-

- Hussein, Shallouf. (2006). Al-Mutanabbi's Wisdom between Mentalism and Technical Requirements, Master Thesis, Faculty of Arts and Languages, University of Manchouri, Algeria.

- Jacariga Keita and Ismail Mohamed Zaid (2017), Standard Specifications Introduction to Developing the Arabic Grammar Curriculum in the Light of Quality Standards, Journal of Human and Social Sciences Generation, No. 35

- $\quad$ Jeste, D. V., Ardelt, M., Blazer, D., Kraemer, H. C., Vaillant, G., \& Meeks, T. W. (2010). Expert consensus on characteristics of wisdom: A Delphi method study. The Gerontologist, 50, 668-680.

- Jordan, J. (2005). The quest for wisdom in adulthood: A psychological perspective. In R. J. Sternberg \& J. Jordan (Eds.), A handbook of wisdom. Psychological perspectives. (pg. 160- 188). New York: Cambridge University Press.

- $\quad$ Kamel, Mohamed Ahmed (2013) .Evaluation of rhetorical questions in the light of reflective thinking skills for the first grade of secondary school, Journal of the Faculty of Education, Port Said University, No. 14-June

- Kunzmann, U. (2004). Approaches to a good life: The emotional-motivational side to wisdom. In P. A. Linley \& S. Joseph (Eds.), Positive psychology in practice (pp. 504-517). Hoboken, NJ: Wiley. 
- Mahmoud, Mohammed Abdul Rahman. (2014). The Poetry of Wisdom and Asceticism in the Age of Sects, Journal of the College of the Great Imam (may Allaah have mercy on him), No. 18, pp. 69-112

- $\quad$ Mansour, Samah Mohammed Moheb Abdo. (2014). A Proposed Concept for Developing the Arabic Language Curriculum in the Secondary Stage in Egypt in the Light of the Results of Educational Research and its Future Trends from 2000-2011, PhD Thesis, Faculty of Graduate Studies of Education, Cairo University

- $\quad$ Mickler, C., \& Staudinger, U. M. (2008). Personal wisdom: Validation and agerelated differences of a performance measure. Psychology and Aging, 23(4), 787-799

- $\quad$ Ministry of Education (2007). Education for All: Medium Term Report 20002007, Cairo National Center for Educational Research and Development.

- $\quad$ Mohamed Shafie El-Din, (2016) Towards a Proposed Approach to the Study of Arabic in Secondary Education, Conference of the Arabic Language Academy in Cairo at its Eighty-second Session, "The Reality of Arabic in Arab Societies: Causes and Confrontation, Arabic Language Complex, Cairo."

- Mohammed Khalifa Nasser, the surgeon Abdel Nasser Diab, and Bishara Mowaffak Selim. (2013). The Predictive Power of Multiple Intelligences at the Level of Wisdom among University Students in Jordan, Journal of the Union of Arab Universities for Education and Psychology, Volume XI, First Issue, pp. 110-136.

- Muhammad, Khansa' Dieb al Jaji.(2017) The wisdom in the poetry of Mahmoud Sami Baroudi, Journal of Islamic \& Religious Studies, Journal of Islamic \& Religious Studies, JIRS, Vol.:2, Issue: 2

- $\quad$ Nidal Ghawader (2016). Evaluation of the New Palestinian Arabic Curriculum for the Tenth Grade from the Perspective of Teachers in Hebron Governorate, Journal of the Faculty of Basic Education for Educational and Human Sciences, Issue 26, University of Babylon April 2016 
- $\quad$ Richardson, M. J., \& Pasupathi, M. (2005). Young and growing wiser: Wisdom during adolescence and young adulthood. In J. Jordan \& R. J. Sternberg (Eds.), A handbook of wisdom: Psychological perspectives (pp. 139-158). Cambridge, UK: Cambridge University Press.

- $\quad$ Shaheen, Joudah (2010) .Prediction of Personal Intelligence from Academic Compatibility and Decision Making among a Sample of Female Students at the College of Education in Saudi Arabia, Psychological Studies, Vol. 20, No. 2, April. Pp. 357--396.

- Shawqui, T. (2006). Psychology and cognitive societal development. Cairo: Dar Ghareeb for Printing and Publication.

- $\quad$-Shoura, Ghada Khaled. (2013). The degree of application of the skills of flexibility and clarification in the teaching of Arabic language and its impact on the achievement and linguistic intelligence of the ninth grade students in the Jordan Theban Brigade, MA, Faculty of Educational Sciences University of the Middle East.

- $\quad$ Shraideh, Mohammed Khalifa Nasser. (2015). The Level of Metacognitive Thinking and Wisdom among a Sample of University Students and Their Relationship, The Jordanian Journal of Educational Sciences, Vol. 11, No. $4,403-415$

- $\quad$ Staudinger, U.M., Glück, J., 2011. Psychological wisdom research : Commonalitiesand differences in a growing field. Annual Review of Psychology 62 (1), 215-241.

- $\quad$ Sternberg J. Robert ،2012، Historique Teaching for Wisdom, Tufts University ,http://www.thanh-nghiem.fr/tiki-

- $\quad$ Sternberg Robert J. ,(2009).Academic Intelligence Is Not Enough WICS: An Expanded Model For Effective Practice In School And Later in Life, A paper commissioned for the conference on Liberal Education And Effective Practicum, Mosakowski Institute for Public Enterprise, March 12-13, 2009 
- $\quad$ Sternberg, R. J. (2001). Why schools should teach for wisdom: The balance theory of wisdom in educational settings. Educational Psychologist, 36(4), 227-245.

- $\quad$ Sternberg, R. J. (2003). Wisdom, Intelligence, and Creativity Synthesized, New York: Cambridge University Press

- $\quad$ Sternberg, R. J. (2005). Foolishness. In R. J. Sternberg \& J. Jordan (Eds.), Handbook of wisdom: Psychological perspectives, New York: Cambridge University Press.

- $\quad$ Sternberg, R. J. (2005). Older but not wiser? The relationship between age and wisdom.Ageing International, 30(1), 5-26.

- The Ministry of Planning. Sustainable Development Strategy Egypt Vision 2030 (Goals and Performance Indicators), Conference on Supporting and Developing the Egyptian Economy, 13-15 March, Sharm El Sheikh

- Uberman, Agnieska (2010), ,Vocabulary As A Reflection OF Life Wisdom, Institute of English Studies University of Rzeszów, available at: https://www.pulib.sk/web/kniznica/elpub/dokument/Balogova1/subo $\mathrm{r}$

- We Xiaoxia (January - April 2006).Wisdom Approach To English Language Teaching, ABAC Journal Vol.26, No. 1 , pp. 19 - 30

- Webster,J.D.(2007).Measuring the character strength of wisdom. Againg and Human development.vol.65.2,163-183 